Chapter 14

\section{The Neural Substrates of Cognitive Event-Related Potentials: A Review of Animal Models of P3}

Ken A. Paller

One reason to study the electrical activity of the brain is that the knowledge gained might be useful for understanding the neural basis of cognitive functions. In other words, endogenous or cognitive event-related potentials (ERPs), which are averaged field potentials that are sensitive to manipulations of psychological variables, could provide evidence to constrain theories on the brain mechanisms that mediate cognition. The success of this approach, however, depends on the extent to which two types of relationships can be substantiated: relationships between ERPs and theories of cognition and relationships between ERPs and particular neural events, structures, or systems. Although cognitive ERPs have been thoroughly characterized only in humans, critical evidence for clarifying the neurophysiological substrates of cognitive ERPs may come from studies in animals (Galambos and Hillyard, 1981). This review focuses on recent studies that have begun to develop animal models of a particularly well-characterized cognitive ERP, the P3 or P300 potential. To develop criteria for assessing these animal models, the characteristics of P3 in humans are first outlined. Evidence pertaining to the adequacy of each of the putative animal models is then discussed by species, along with evidence about the neural basis of these ERPs. The concluding section will reflect on prospects for understanding the neural basis of $\mathrm{P} 3$ and on the usefulness of the animal approach.

\section{Studies of P3 and Its Neutral Substrates in Humans}

P3 was first described by Sutton and colleagues (Sutton et al., 1965, 1967), who showed that the potential could be elicited by an unexpected stimulus as well as by the unexpected absence of a stimulus. P3 is a positive ERP that typically peaks at about $300 \mathrm{msec}$ or more after an informative stimulus that is delivered unexpectedly (see reviews by Fabiani et al., 1987; Hillyard and Kutas, 1983; Pritchard, 1981). P3 is most commonly recorded during a randomly ordered sequence of stimuli from two classes, such as high- and low-frequency tones. Stimuli from a relatively infrequent class ("oddball" stimuli) reliably elicit $\mathrm{P} 3$ if the subject actively discriminates the stimuli, for example, by counting stimuli from one class. In some cases, P3 can be elicited by oddball stimuli not given explicit relevance (Ritter, Vaughan, and Costa, 1968; Roth et al., 1976; Squires et al., 1977), but often the scalp topography then has a frontal maximum and the peak latency is shorter (e.g., Squires, Squires, and Hillyard, 1975). P3 amplitude tends to decrease when attention is diverted (Wickens et al., 1983), or when the subject is uncertain about having correctly perceived the stimulus (Hillyard et al., 1971; Ruchkin and Sutton, 1978). The latency of $P 3$ is thought to vary with the time required for stimulus evaluation and to be independent of motor processing (Kutas, McCarthy, and Donchin, 1977; McCarthy and Donchin, 1981). For example, P3 to a soft click interspersed in a sequence of loud clicks may peak at a latency of about $300 \mathrm{msec}$, but P3 to a female name in a list of male names may occur at a latency of $500 \mathrm{msec}$ or greater. P3 can be elicited by stimuli in auditory, visual, or somatosensory modalities (Desmedt and Debecker, 1979; Simson, Vaughan, and Ritter, 1977; Snyder, Hillyard, and Galambos, 1980).

Hypotheses about specific information processing events that are indexed by $\mathrm{P} 3$ have been developed by coopting a variety of psychological constructs, although a consensus on this issue has not been reached (e.g., see Verleger, 1988, and associated commentaries). We can nevertheless adopt the working hypothesis that $\mathrm{P} 3$ waves reflect neural events called into play as a part of some physiologically meaningful process or processes. At present, it is impossible to specify the nature or function of these neural events in either physiological or psychological terms, nor is it clear whether different types of P3 waves produced in different task situations reflect identical or different processes. Future advances may bring about a resolution of these issues, but it is likely that advances of this sort will require more knowledge about the neural bases of the potentials.

Empirical support for hypotheses about the anatomical and physiological substrates of $\mathrm{P} 3$ can be derived from detailed mappings of potential fields on the scalp, intracranial recordings, magnetoencephalographic recordings, and studies in neurological patients with known brain lesions. Evidence from field distributions of $\mathrm{P} 3$ on the scalp has been interpreted to implicate certain configurations of intracranial current generators, despite the ambig- 
uity of this "inverse method." The scalp distribution of P3 is broad and bilaterally symmetric, reaches maximal amplitudes at central and parietal sites on the midline, and is relatively independent of stimulus modality. It has been hypothesized that $\mathrm{P} 3$ arises from bilateral generators in parietal association cortex with an additional contribution from frontal cortex (Simson, Vaughan, and Ritter, 1976, 1977). Another suggestion is that diffuse projections from brain stem to cortex play a key role (Desmedt, 1981; Galambos and Hillyard, 1981). A third hypothesis emphasizes the importance of subcortical structures, especially the hippocampus (see below). Extracranial recordings have proven insufficient to differentiate between these three hypotheses.

Intracranial recordings have been obtained from epileptic patients who were candidates for neurosurgery to relieve medically intractable seizures and from a few patients with other neurological disorders (Halgren et al., 1980; McCarthy et al., 1989; Prim, Ojemann, and Lettich, 1983; Smith et al., 1990; Wood et al., 1984; Yingling and Hosobuchi, 1984). The most pervasive intracranial finding has been that ERP waveforms that resemble $\mathrm{P} 3$ can be recorded from medial temporal locations under the same experimental conditions that are used to elicit P3 from the scalp. These highamplitude responses showed steep potential gradients across closely spaced electrodes. This evidence, along with evidence from single unit responses, indicated that electrical activity was locally produced within this part of the brain at the time P3 occurred. It was thus suggested that this activity was volume conducted through brain tissue and made a major contribution to the scalp-recorded P3.

Intracranial data such as these face a number of interpretative problems. One problem is that it is difficult to determine precisely where the electrodes are located with respect to anatomical boundaries. Another problem is that the patients' histories of disordered brain electrical activity and anticonvulsant pharmacotherapy may limit the generalizability of the results. Most importantly, intracranial electrode placements are dictated by clinical considerations such that probes are targeted for areas of suspected pathology. Normal tissue may also be sampled in many cases, but in any given patient only a limited number of areas are examined. Such limited samplings pose difficulties for intracranial field mapping and for conclusively determining the sources of scalp-recorded potentials.

Magnetoencephalographic recordings in normal subjects have been interpreted to confirm the idea that $\mathrm{P} 3$ is generated in the hippocampus (Okada, Kaufman, and Williamson, 1983). In this study, the magnetic field measured using a single sensor moved to various locations around the head showed an event-related response presumed to correspond to the electrical P3. This field approximated that which would be produced by a dipole source in the hippocampus. The assumption of an equivalent dipole source, however, may have been misleading in this case. Further, magnetoencephalo- graphic mapping results from other laboratories have diverged considerably (e.g., Gordon et al., 1987; Richer, Johnson, and Beatty, 1983; Trahms et al., 1990). Indeed, there are many difficulties in using magnetic event-related 1990). Indeed, there are many difficulties in using magnetic eventity to investigate ERP sources, although the situation may be improved by multichannel recording and by advances in modeling techniques, such as by multichannel recording and by advances localization in a multiple dipole model (e.g., Dale and Sereno, 1993). In some circumstances, magnetic and model (e.g., Dale and Sereno, 1993). In some circumstan techniques can be used in a complementary manner by exploiting their differential sensitivities (e.g., magnetic recordings are relatively more their differential to tangential versus radial sources). Moreover, some sources of an electrical signal may not yield an appreciable magnetic signal. Therefore, the electrical signa ERP are likely to differ from the sources of the corresponding magnetoencephalographic signal, which underscores the need for biologically accurate source modeling.

ERP studies in patients with known brain lesions can provide evidence that is more direct, although interpretations must take into account confounding factors such as conductivity changes from skull defects and scar tissue. Still, lesion evidence has convincingly implicated a selective role for the frontal lobe in modulating P3 (Knight, 1984). Patients with unilateral prefrontal lesions exhibited normal P3 waves to target stimuli but not to novel, nontarget stimuli. Another lesion study suggested that neocortex in the superior temporal plane plays an important role in the system that the superior temporal plane p89). This study showed that P3 was unaffected by lesions of the lateral parietal lobe, whereas lesions of the parietotemporal junction were associated with large decrements in P3. However, it is presently unclear why unilateral lesions were associated with a bilateral disruption, given that callosal damage alone does not cause such a disruption (Kutas et al., 1990). Finally, several studies have shown that unilateral temporal lobectomies in epileptic patients have minimal effects on P3 (Johnson, 1988; Stapleton, Halgren, and Moreno, 1987; Wood et al., 1982). In addition to these findings from epileptic patients with unilateral damage, normal P3 potentials have also been recorded from a patient with unilateral medial temporal damage due to a tumor (Rugg et al., 1991) and from patients with bilateral medial temporal damage due to encephalitis (Onofrj et al., 1991, 1992; Potter et al., 1993). In sum, lesion studies have contributed to our understanding of the neural generation of $\mathrm{P} 3$, although the data are still consistent with a large number of alternative hypotheses.

\section{Animal Models of P3}

A clarification of the neurophysiological substrates of P3 may require some synergism between studies in humans and studies in nonhuman animals. Many types of evidence could be used to argue that homologous brain 
circuitry in different species produces the same sort of electrical fields. Such evidence could include intracranial field analyses, current source density analyses, correlations between ERPs and unit activity, stimulation experiments, pharmacological experiments, and tests with brain lesions. In animals, these techniques can often be applied in a more systematic manner than in humans, yet the decision to conduct invasive experimentation should not be taken lightly. Can adequate justification be achieved by weighing possible benefits against costs? Some benefits are readily anticipated. For example, an increase in the clinical utility of cognitive ERPs may develop from learning about their neural substrates. In contrast, long-term benefits can be difficult to foresee because they may depend on discoveries yet to be made. (A corollary of this idea is that future technical advances could obviate the need to rely on some of today's invasive techniques.) Given that the benefits of any particular research direction can seldom be determined with certainty a priori, limiting our goals to short-term, practical applications would stifle many scientific advances. Although the costs of using animals in research can similarly be difficult to determine, steps can be taken to minimize discomfort and other disadvantages of living in captivity. Indeed, the key ingredient for dealing with the costs may be compassion. Further, advances in comparative psychology are giving us a deeper understanding of the complexity of the cognitive capabilities of animals (e.g., Cheney and Seyfarth, 1992), which underscores the need to adequately consider their psychological well-being when used as subjects. It is conceivable that ERP measures themselves may eventually be useful tools for furthering our understanding of cognition in animals (Hillyard and Bloom, 1982).

Rigorously validating a P3-like potential in a nonhuman species would require demonstrating each of the important characteristics of the human P3. Although many characteristics can be listed, there is little consensus about exactly which ones are necessary or sufficient for unambiguously identifying the $\mathrm{P} 3$ component. Still, it may be helpful to subdivide the features of P3 into three categories. (1) The functional characteristics strive toward integrating the measure into models of information processing and generally constitute task manipulations known to influence P3. (2) The waveform characteristics include latency, polarity, amplitude, and wave shape. (3) The neural characteristics refer more directly to the particular neural elements responsible for the ERP. There is room for a great deal of improvement in our understanding of the neural characteristics of $\mathrm{P} 3$, and this knowledge will ultimately be necessary for confirming the validity of the animal models.

Of course, assessing the waveform characteristics of P3-like ERPs is the most straightforward way to begin. Whenever feasible, however, neural and functional characteristics should be weighed more heavily in evaluating the animal models, because waveforms may vary with anatomical or morphological differences between species that may be irrelevant to brain function. A tentative list of functional characteristics that may be useful for this purpose is given in Table 1. Because these characteristics have been derived from
Table 1. Functional criteria for P3-like ERPs in animals

1. Elicited by relatively unpredictable stimuli

a. amplitude proportional to degree of unpredictability b. amplitude responsive to sequential patterns

2. Requires that attention is allocated to stimulus processing a. elicited by imperative stimuli in categorization tasks b. amplitude can be controlled by task requirements

3. Stimulus modality not critical

a. elicited by auditory stimuli

b. elicited by visual stimuli

c. elicited by somatosensory stimuli

d. elicited by semantically defined categories

e. elicited by stimulus omissions

4. Latency increases with complexity of discrimination

a. latency can vary with modality

b. latency relatively independent of motor processing

manipulations of experimental parameters in $\mathrm{P} 3$ experiments, parallel tasks are important for assessing the animal models. The oddball task, in particular, has been central to the study of P3. In this task, a discriminative response is made to one type of stimulus. An animal can be trained to perform such a task through the use of operant conditioning. The behavioral response can then be used to infer that the animal is devoting attention to processing the stimuli. This sort of task, here termed a categorization task, can be distinguished from two other types of tasks that have also been used in animal studies. In a conditioning task, animals undergo procedures that may lead them to pay attention to stimuli, but, unlike the categorization paradigm, classical conditioning is used and the behavioral response initially occurs automatically. After training, the conditioned response is monitored to infer that the animal is processing the stimulus to some extent, but it may not be safe to assume that stimulus processing is equivalent to that in a categorization task. Because conditioning paradigms have rarely been used in studies of $\mathrm{P} 3$ in humans, they provide relatively weaker evidence for validating an animal model. Nevertheless, further evidence (such as waveform similarities across tasks) may be used to substantiate the P3-like responses that are recorded in conditioning tasks. A parallel argument applies to the last type of task, a passive task, in which no behavioral responses are made and the stimuli presented have no conditioned significance. Despite these uncontrolled circumstances, some investigators have found that animals may nonetheless exhibit P3-like responses.

When referring to the putative animal models, the phrase "P3-like ERPs" is used to avoid prejudging the relationship between the ERPs and P3 in humans. Incidentally, some early experiments in animals revealed P3-like ERPs that were not explicitly recognized as such (e.g., Donchin et al., 1971; Fuster et al., 1982; Galambos and Sheatz, 1962; John, 1963). The 
Table 2.

\begin{tabular}{|c|c|c|c|}
\hline \multirow[b]{2}{*}{ Animal } & \multicolumn{3}{|c|}{ Paradigm used to elicit P3-like ERPs } \\
\hline & Categorization & Conditioning & Passive \\
\hline $\begin{array}{l}\text { Macaque } \\
\text { monkey }\end{array}$ & $\begin{array}{l}\text { Arthur and Starr, } 1984 \\
\text { Paller et al., 1988, } 1992 \\
\text { Glover et al., } 1991\end{array}$ & $\begin{array}{l}\text { Glover et al., 1986, } 1988 \\
\text { Onofrj et al., } 1987\end{array}$ & Paller et al., 1982, 1988 \\
\hline $\begin{array}{l}\text { Squirrel } \\
\text { monkey }\end{array}$ & Pineda et al., 1988 & & $\begin{array}{l}\text { Neville and Foote, } 1984 \\
\text { Pineda et al., 1987, } 1989 \\
\text { Swick et al., } 1991\end{array}$ \\
\hline Cat & & $\begin{array}{l}\text { Wilder et al., } 1981 \\
\text { Buckwald and Squires, } 1982 \\
\text { O'Conner and Starr, } 1985 \\
\text { Katayama et al., 1985a, b } \\
\text { Harrison et al., 1985, etc. } \\
\text { Csépe et al., } 1987\end{array}$ & $\begin{array}{l}\text { Başar-Eroglu et al., } \\
\text { 1987, 1991a, 1991b }\end{array}$ \\
\hline Rabbit & $\begin{array}{l}\text { Aleksandrov and } \\
\text { Maksimova, } 1985\end{array}$ & $\begin{array}{l}\text { Weisz et al., } 1983 \\
\text { Stolar et al., } 1989\end{array}$ & \\
\hline Rat & $\begin{array}{l}\text { Brenner et al., } 1987 \\
\text { Voorn et al., } 1987\end{array}$ & Hurlbut et al., 1987 & $\begin{array}{l}\text { O'Brien, } 1982 \\
\text { Hurlbut et al., } 1987 \\
\text { Yamaguchi et al., } 1993\end{array}$ \\
\hline Dolphin & & Woods et al., 1986 & Woods et al., 1986 \\
\hline Dog & & Koslov and Pirogov, 1988 & \\
\hline
\end{tabular}

focus here is on studies explicitly designed to examine animal models of $\mathbf{P} 3$. Recordings were made from chronically implanted epidural electrodes unless otherwise specified. Table 2 shows which paradigms have been used to elicit P3-like ERPs in animals. Methodological differences between studies were such that any ERP differences across species are difficult to interpret, so rather than highlight these differences, emphasis is given to the high degree of similarity between ERP results from different species.

\section{Macaque Monkey}

The steps toward establishing an animal model of $\mathrm{P} 3$ have been approximated most closely in studies with several species of Old World monkey, all from the genus Macaca. In general, P3-like responses could be elicited in each of the three types of paradigms.

Categorization tasks were first used in the auditory modality. A pitch discrimination was required in these tasks, as monkeys were trained to respond to a pure tone of a particular frequency by releasing a lever (Fig. $1)$. These target tones occurred relatively infrequently $(p=.1)$ in a sequence of nontarget tones $(p=.9)$. Late positive ERPs were elicited by target tones
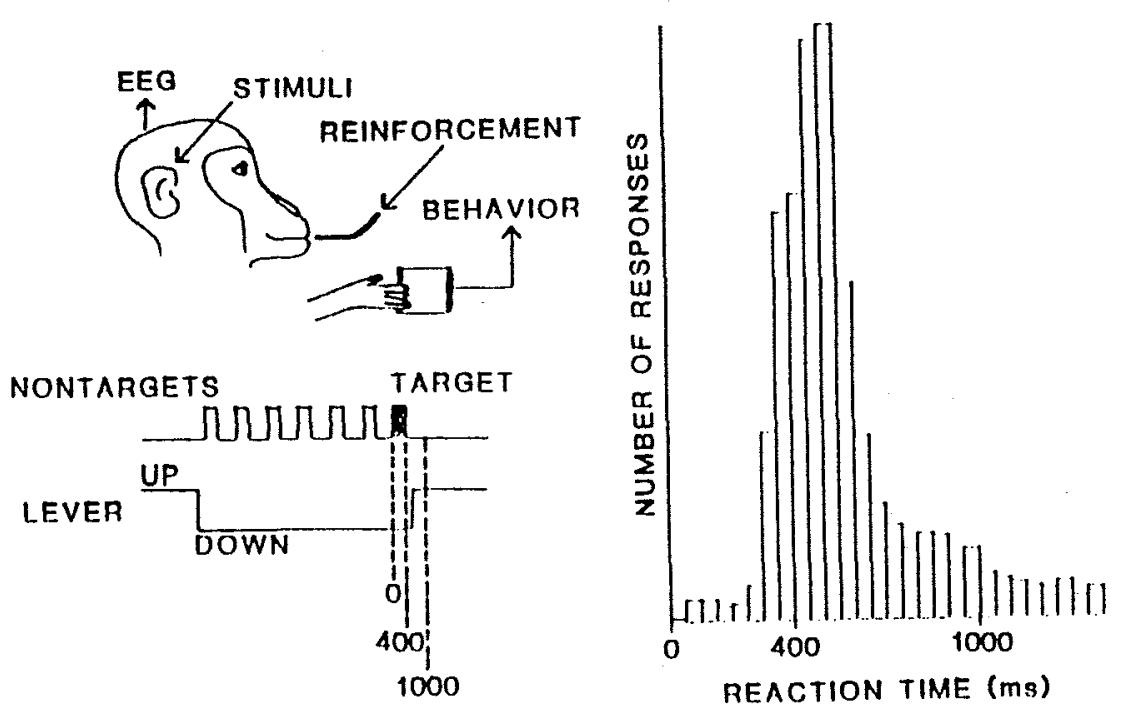

Figure 1. Schematic diagram of auditory categorization task. Monkey pulled lover to initiate sequence of nontarget tones. After pseudorandom number of tones, lever to initiate sequence of nontarget tones. After pseudorandom number of tones,
target tone of different frequency occurred. Monkey released lever in 400- to $1000-\mathrm{msec}$ interval to receive juice reinforcement. Bar graph shows that most responses occurred in this interval. (From Paller, 1986.)

in Macaca nemestrina (Arthur and Starr, 1984) as well as in Macaca in Macaca nemestrina (Arthur and Starr, 2). As shown in Figure 2, the amplitude of this ERP decreased when the probability of the rare tone was increased. The amplitude also decreased when the stimuli were presented while the response could not be executed. Other manipulations showed that the P3-like ERPs were contingent on the infrequent nature of stimuli rather than on particular physical stimulus parameters. Comparisons between ERPs from intact monkeys and monkeys with brain lesions showed that the hippocampus, amygdala, and overlying neocortical areas were not critical for the elicitation of normal P3-like responses (Paller et al., 1988).

Categorization paradigms in the visual modality have also been used Surface and depth recordings were made in monkeys (Macaca mulatta) trained to touch stimuli presented on a video monitor with a touch-sensitive screen (Paller et al., 1992). Three types of stimuli were presented: a blackand-white checkerboard target $(p=.1)$ and two nontarget stimuli, a gray square and a red-and-white checkerboard ( $p=.8$ and .1 ,respectively). These square and a red-and-white checkerboard $p=$ differed from one nontarget primarily in form and from the other nontarget primarily in color, which primarily in form and from the other nontion to making the discrimination (Treisman and Gelade; 1980). Targets elicited P3-like potentials from 


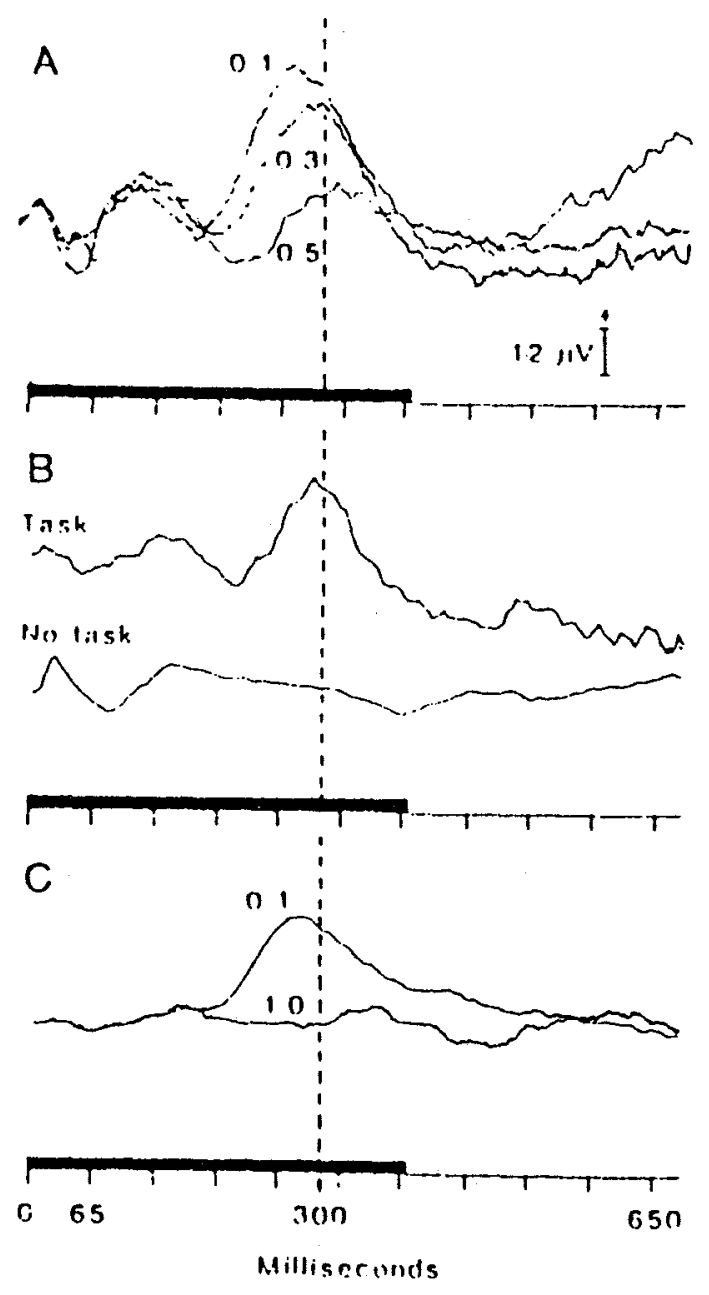

Figure 2. ERPs elicited by target in an auditory categorization paradigm. A. ERPs averaged from two monkeys show a late positive component that increased in amplitude inversely with probability of target. B. ERPs averaged across three midline electrodes in one monkey show that P3-like ERP was elicited during performance of task but not when task could not be performed. C. ERPs averaged across three midline electrodes in one monkey show that P3-like ERP was not elicited when $100 \%$ of tones were targets. Reprinted with permission of the AAAS from Arthur DL, Starr A (1984): Taskrelevant late positive component of the auditory event-related potential in monkeys resembles P300 in humans. Science 223: 186-188. Copyright 1984 by the AAAS.

epidural contacts and corresponding negative potentials from depth contacts in the medial temporal lobe (Fig. 3). The epidural ERPs reached positive peaks between 260 and $300 \mathrm{msec}$, while negative peaks in the medial temporal lobe tended to occur slightly later. This correspondence between surface and depth responses has also been reported in P3 studies conducted in epileptic patients with electrodes implanted for seizure monitoring (McCarthy et al., 1989). However, the resolution with which recording electrodes could be localized was much greater in monkeys, suggesting that questions about the physiological substrates of the potentials may be resolved by further field mapping in monkeys.

In another visual paradigm, monkeys (Macaca fasicularis) were trained to respond to sinusoidal gratings of a particular orientation (Glover et al., 1991). P3-like ERPs were elicited by target stimuli that were infrequent

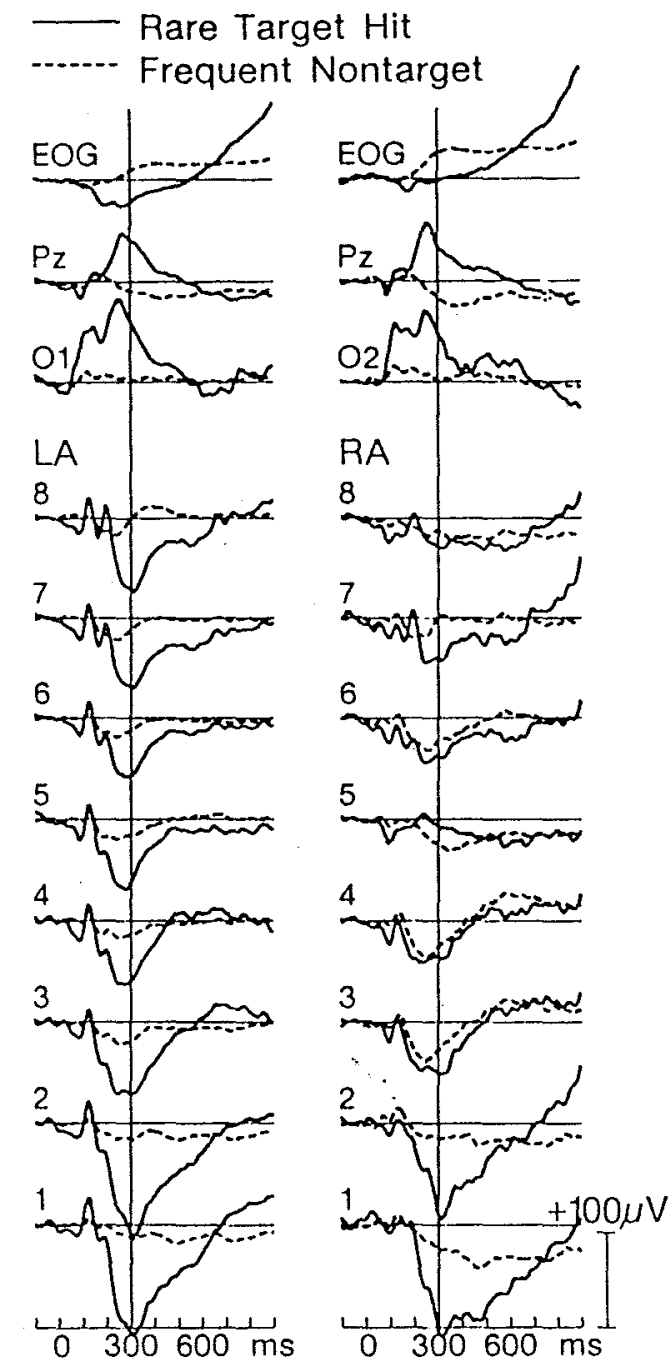

Figure 3. ERPs elicited from a monkey during a visual categorization paradigm. From epidural electrodes, a late positive ERP was elicited by rare targets that were detected (i.e., touched) but not by frequent nontargets. Left column: recordings from first half of session; right column: recordings from second half of session. ERPs from $\mathrm{Pz}$ are quite similar between halfsessions. Recordings from many contacts in the left anterior (LA) medial temporal lobe and the right anterior (RA) medial temporal lobe show negative deflections during latency of P3-like ERPs. Reprinted with permission from Elsevier Science Publishers, Inc. from Paller et al. (1992).

$(p=.3)$ or equiprobable $(p=.5)$ but not when they were continual $(p=1.0)$. Results from 1 monkey trained to make a delayed response showed that P3-like ERPs were similar whether the mean reaction time was near $600 \mathrm{msec}$ or $900 \mathrm{msec}$. Similar P3-like ERPs in visual categorization paradigms have also been recorded by other investigators (Antal et al., 1993; Arthur, 1985; S. Grant, personal communication).

Monkey ERPs have also been studied using a conditioning paradigm (Glover et al., 1986). Tones of two frequencies were presented, and the rare tone ( $p=.2$ ) was followed $700 \mathrm{msec}$ later by a mild shock (the intensity of which was adjusted to a level that produced a hind-paw twitch "without 
obvious autonomic effects"). The late positive ERP showed a maximum amplitude at $314 \mathrm{msec}$ at a central midline electrode. This ERP appeared after 3-5 training sessions, and its amplitude was proportional to the probability of the rare tone (across manipulations from $p=.5$ to $p=.1$ ). The ERP decreased in amplitude during extinction sessions when conditioning was discontinued. The authors also noted that after 12 conditioning sessions the amplitude of P3-like ERPs tended to decrease during a single session even though hind-paw movements in response to the shock were stable. Further studies with this paradigm have shown that the P3-like ERPs were abolished in animals suffering from a temporary Parkinsonian syndrome caused by the administration of the neurotoxin MPTP (Glover et al., 1988). Levodopa treatment was used to alleviate the motor symptoms, but it did not bring back the P3-like ERPs. In clinical studies with humans, alterations of P3 have been associated with idiopathic Parkinson's disease, although these alterations may only occur when the disease includes a dementia component (Goodin and Aminoff, 1987). Other evidence also supports the hypothesis that $\mathrm{P} 3$ alterations can index Parkinsonian dementia by reflecting a cholinergic rather than a dopaminergic deficiency (see Bodis-Wollner, 1990). In a study with the drug L-acetylcarnitine, which may lead to improvements in patients with dementia via a cholinergic mechanism, the amplitude of P3-like ERPs in the conditioning paradigm was found to increase, along with a less consistent decrease in latency (Onofrj et al., 1987, but see Antal et al., 1993). Overall, the conditioning paradigm is useful because P3-like ERPs can be recorded after very few training sessions, but longitudinal studies may be problematic because responses tend to habituate.

Auditory stimuli in passive paradigms have also been used to elicit P3-like ERPs (Paller et al., 1982, 1988). In one paradigm, three types of tone were presented: a frequent pure tone $(p=.8)$, a rare pure tone $(p=.1)$, and a rare complex tone $(p=.1)$. Tones were randomly ordered in a sequence presented at a 1 -sec interstimulus interval (ISI). Figure 4 juxtaposes late

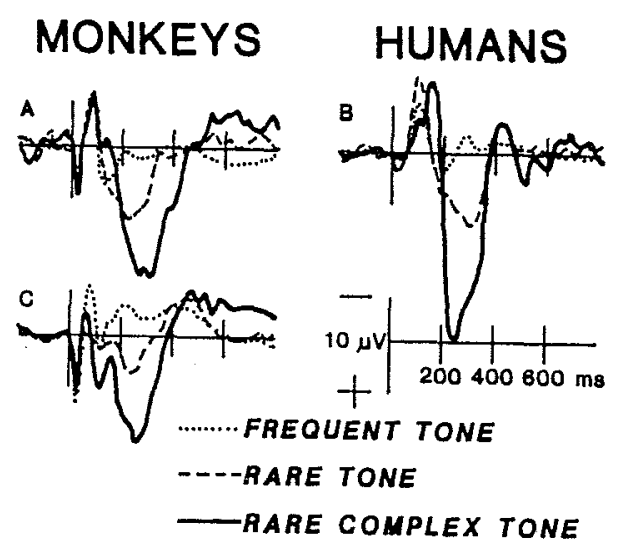

Figure 4. ER Ps elicited during a passive paradigm from groups of five intact monkeys (A), five human subjects (B), and five monkeys with medial temporal lobectomies (C). P3-like ERPs were elicited by rare tones in all groups. Medial temporal lobe structures appear to be unnecessary for generation of normal P3-like ERPs. (See Paller et al., 1988.) positive ERPs elicited from monkeys (Macaca fasicularis) with and without medial temporal lobectomies, and ERPs from human subjects. In the intact monkeys, the P3-like response to the rare complex tone reached a peak at $278 \mathrm{msec}$ at $\mathrm{Cz}$. Waveform characteristics were highly similar between monkeys and humans. The topography of the P3-like ERPs across electrodes (e.g., maximal amplitude at the central midline) also resembled the distribution of P3 recorded from scalp electrodes in human subjects under analogous circumstances. The authors hypothesized that monkeys tended to pay attention to the stimuli, although there were no task requirements to do so.

In summary, P3-like ERPs have been found in several macaque species. The peak amplitude of these positive responses generally occurred at a latency between 260 and $350 \mathrm{msec}$. Similar ERPs were elicited by auditory and visual stimuli, although responses to visual stimuli tended to be somewhat later than those to auditory stimuli, as is the case for P3 in humans. In direct comparisons, P3-like ERPs in monkeys bore a strong resemblance to $\mathrm{P} 3$ waves recorded from human subjects under comparable circumstances.

P3-like ERPs were found in each of the three types of experimental paradigm. However, some results in the passive paradigm showed that P3-like ERPs tended to habituate across sessions (Paller, 1986), whereas in other cases P3-like ERPs were never found (Glover et al., 1986). Similarly, passive conditions have led to variable results in human subjects (Donchin and Cohen, 1967; Ford, Roth, and Kopell, 1976; Polich, 1989b; Ritter, Vaughan, and Costa, 1968; Roth et al., 1976; Smith et al., 1970; Squires et al., 1977). The reliability of $\mathrm{P} 3$ may depend on the extent to which attentional resources are devoted to processing the stimuli. Such a dependence on attention is strongly supported by results from experiments in which human subjects performed two tasks concurrently (Wickens et al., 1983). In monkeys, P3-like ERPs may be elicited in passive conditions only if circumstances are such that monkeys tend to pay attention. Factors such as prior experience in testing situations and the monkeys' level of stress may play a role in determining whether they are attentive to the stimuli. Similarities between ERPs in the different paradigms nevertheless support the hypothesis that the underlying processes have much in common.

Response habituation can occur in passive and conditioning paradigms because of the lack of sufficient attentional requirements, whereas categorization paradigms minimize this problem and also duplicate the standard conditions for eliciting P3 in humans. Although P3 amplitude in humans has been shown to decline slightly during the course of a prolonged categorization paradigm (Polich, 1989a), the available evidence suggests that robust P3-like ERPs can still be elicited after multiple training sessions in monkeys. On the negative side, the use of reinforcement can exacerbate problems with response artifacts. Elaborate techniques to control eye movements are available, but without these, animals can produce electroocular and other artifacts that are time-locked to the stimulus of interest. It is therefore crucial either to eliminate these artifacts through training or to 
record them in a manner that allows contaminated trials to be eliminated. In general, the evidence from the studies cited above suggests that P3-like responses did not arise artifactually.

\section{Squirrel Monkey}

In the squirrel monkey (Saimiri sciureus), a New World monkey, P3-like ERPs have been recorded in passive and categorization paradigms. In passive auditory paradigms, positive ERPs in the 300 - to 800 -msec latency range were elicited by infrequent auditory stimuli with no conditioned significance (Neville and Foote, 1984; Pineda, Foote, and Neville, 1987; see also Ehlers, 1988, 1989). In one paradigm, rare tones $(p=.08)$ in a sequence of frequent tones $(p=.92)$ elicited a broad positivity beginning at about $300 \mathrm{msec}$ and continuing for several hundred milliseconds. In another paradigm, a second type of rare stimulus (an edited dog bark that resembled the complex tone referred to above, $p=.08$ ) elicited a larger positivity with a sharper peak at $470 \mathrm{msec}$ (Fig. 5). When two equiprobable tones were presented, the amplitude of P3-like ERPs was shown to depend on the sequential ordering of the stimuli as has been reported for $\mathrm{P} 3$ in humans
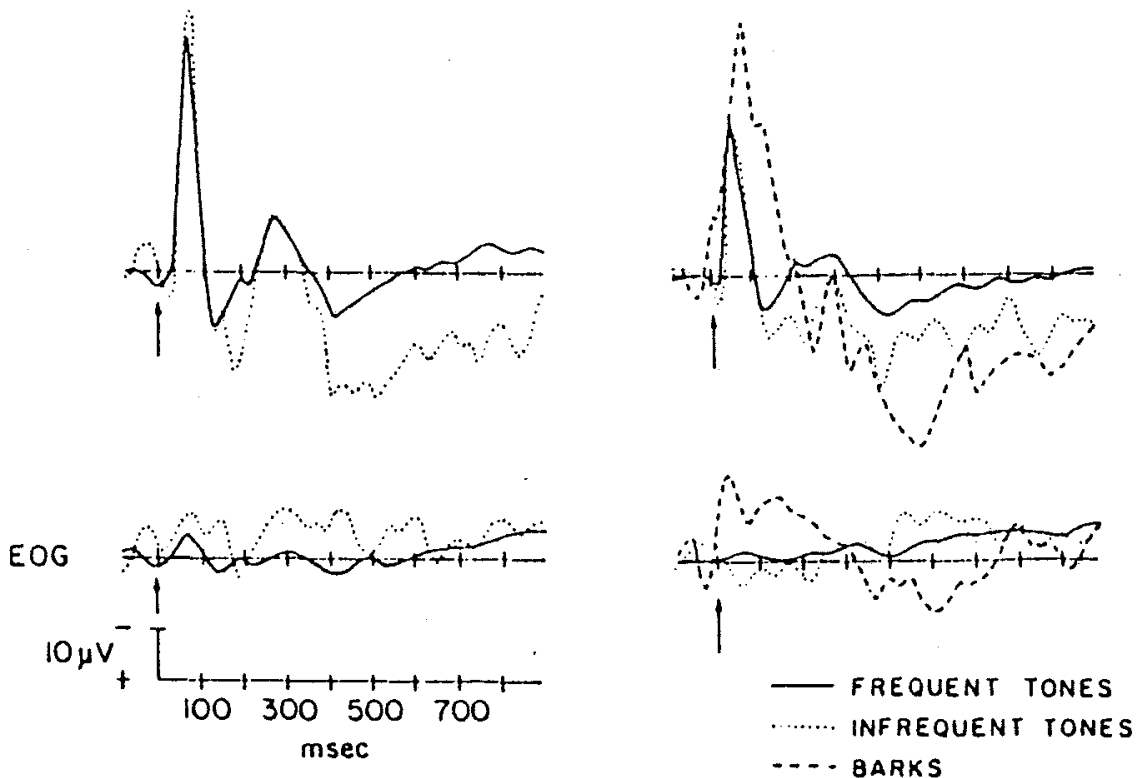

Figure 5. ERPs elicited during two passive paradigms from squirrel monkeys. Left: in P3-like ERPs were elicited by an infrequent tone; right: in P3-like ERPS were elicited by an infrequent tone as well as by an infrequent stimulus resembling a bark. Reprinted with permission of Elsevier Science Publishers from Neville HJ, Foote SL (1984).
(Squires et al., 1976; similar sequential effects have been found in macaques, see Arthur, 1985; Paller, 1986). The positivity resembled P3 waves elicited by the same stimuli in human subjects, except that the latency was greater and the distribution was somewhat different. Unlike the distribution of P3 in humans, P3-like ERPs in squirrel monkeys were very small at midline electrodes and maximal at lateral parietal electrodes, with a tendency to be larger over the right hemisphere. These distributional differences could arise either because of different generators in the two species or because homologous generators are arranged differently in the squirrel monkey. A relevant observation may be that the squirrel monkey cortex is less gyrencephalic than macaque or human cortex.

ERPs in the squirrel monkey have also been studied in an auditory discrimination task similar to the one used in macaques (Pineda et al., 1988). In this paradigm, monkeys were recorded for pulling a lever following rare target tones $(p=.1)$ but not frequent tones $(p=.9)$. The target elicited a broad P3-like ERP in the 200- to 450-msec latency range. The distribution along the cortical surface was similar to that in the passive paradigm, with larger amplitudes at lateral locations than at midline locations, except that in the categorization paradigm, large P3-like potentials were also found at frontal midline locations. Interestingly, ERPs were extremely different in a variation of the task in which frequent tones were omitted. Target tones occurred at approximately the same ISIs (i.e., $4-8 \mathrm{sec}$ ), and responses were only rewarded during periods in which a small light was illuminated. Targets elicited a broad negative deflection that began at about $200 \mathrm{msec}$ and continued for $250-550 \mathrm{msec}$; this is the same latency range in which positive, P3-like responses were elicited in the other paradigms. In human subjects, $\mathrm{P} 3$ potentials elicited by targets presented in the absence of nontargets were highly similar to $\mathrm{P} 3$ potentials in a conventional categorization task (Becker and Shapiro, 1980; Scott et al., 1989). It is presently unclear whether this difference between results in squirrel monkeys and results in humans reflects a species difference or critical differences in the paradigms used.

P3-like ERPs in squirrel monkeys have also been studied to determine whether they are dependent on the noradrenergic nucleus locus coeruleus. In a lesion study using the passive paradigm, conjoint damage to cell bodies in the nucleus and ascending axons from the nucleus $(n=3)$ resulted in a large decrease in the amplitude of the P3-like response, whereas damage to the axons alone $(n=2)$ had no consistent effect (Pineda, Foote, and Neville, 1989). Convergent results were found in one study using a pharmacological manipulation in which clonidine, which suppresses locus coeruleus firing, produced a decrement in P3-like ERPs elicited by auditory stimuli (Swick, Pineda, and Foote, in manuscript). In a subsequent study, however, the same dose of clonidine had no effect on P3-like ERPs elicited by visual stimuli (Pineda and Swick, 1992). Evidence from unit recordings in Macaca fasicularis also suggests a dissociation between locus caruleus activity and P3-like potentials (S. Grant, personal communication; Swick, Pineda and 
Foote, 1991). Although the notion of a direct relationship between P3 and locus coeruleus firing is intriguing, strong empirical support for the hypothesis is lacking.

Cat

Conditioning paradigms have been relied on in several studies with cats. In cats paralyzed with gallamine, a late positive ERP was elicited by auditory or visual stimuli that had been paired with tail-shock (O'Conner and Starr, 1985; Wilder, Farley, and Starr, 1981). Tones of two frequencies were presented at a 2 -sec ISI, and the low-frequency tone $(p=.2)$ was designated the signal. Conditioning began after an habituation session (a passive paradigm), during which P3-like ER Ps were not apparent. During conditioning sessions, a $300-\mathrm{msec}$ shock was delivered $700 \mathrm{msec}$ after the signal. After 200-300 signal presentations, the signal was associated with a conditioned pupillary response that began at a latency of about $300 \mathrm{msec}$ (Fig. 6). P3-like ERPs peaked at a latency somewhat less than $300 \mathrm{msec}$ with the tone signal and at $330 \mathrm{msec}$ in subsequent experiments with the light signal. The amplitude of these ERPs decreased with increased signal probability. Intracranial recordings were also made from various locations using two single-contact probes concurrently. One consistent observation was that negative ERPs in the latency of $\mathrm{P} 3$ were observed at locations in the marginal gyrus and suprasylvian gyrus (the two gyri that run in the anterior-posterior direction near the midline). Late positive and negative ERPs were also found at other intracranial locations, including some in the hippocampus. The distribution of these potentials, however, was difficult to determine precisely because of the lack of concurrent recordings from multiple recording contacts or of evidence to confirm the stability of the intracranial responses over time.

Experiments in a very similar conditioning paradigm were also conducted using multicontact electrode probes that passed through the feline thalamus, as well as in two human patients in whom electrodes were implanted for stimulation therapy to relieve intractable pain (Katayama, Tsukiyama, and Tsubokawa, 1985a). The same conditioning paradigm was used in the two species. Following an habituation session, sequences of high- and low-frequency tones were presented at a 2 -sec ISI. The rare low-frequency tone $(p=.2)$ was paired with a shock that occurred $700 \mathrm{msec}$ after tone onset (delivered to a finger in humans and to the tail in cats). Pupillary responses to the rare tone were used to infer that the two tones were being discriminated at some level by the cats. A P3-like ERP to the rare tone was recorded from the cortical surface. At roughly the same latency, negative ERPs were recorded from electrodes in the thalamus. Negative ERPs with smaller amplitudes were recorded from dorsal contacts in neocortical white matter, while no clear deflections were apparent in recordings from nearby electrodes located ventral to the thalamus. In the patients, the P3 potential elicited by the rare tone reached a peak at about $350 \mathrm{msec}$ at
A.

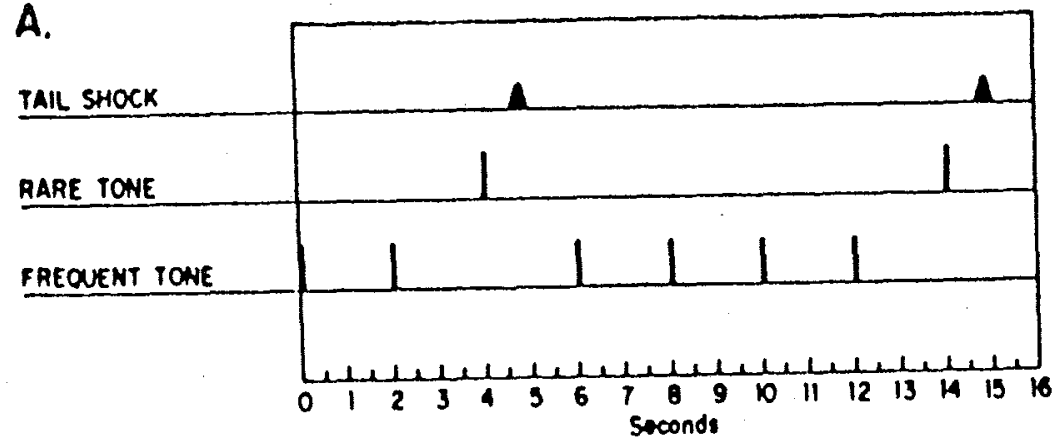

B. SKULL RECORDS

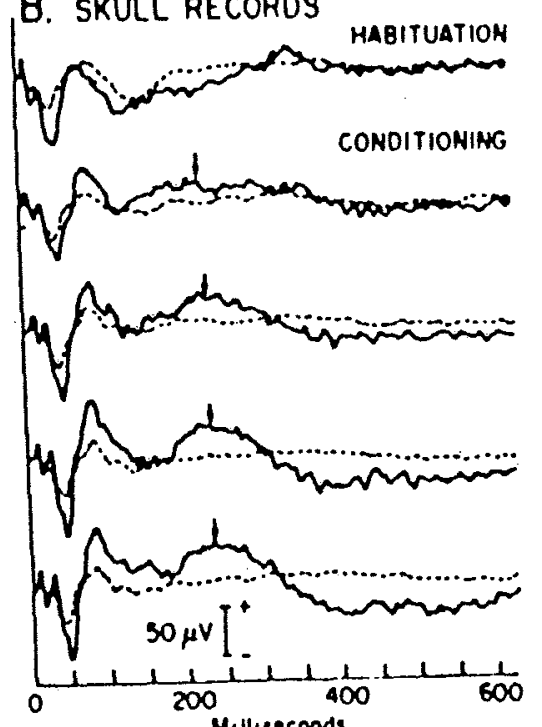

C. PUPIL RESPONSES

HABITUATION

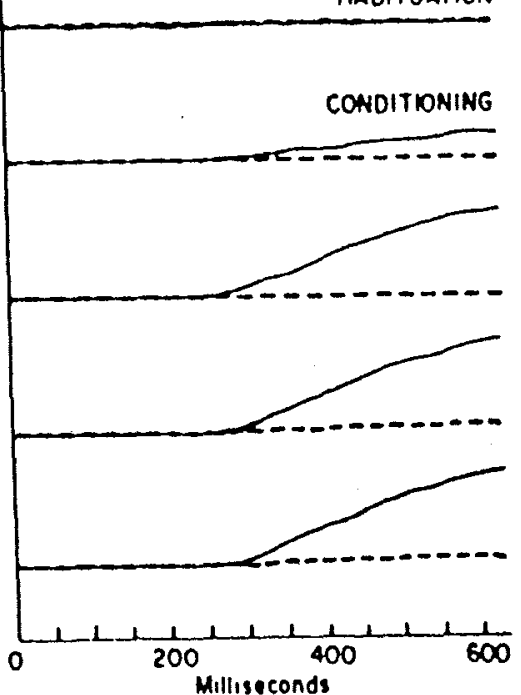

Figure 6. ERPs elicited during a conditioning paradigm in cats. A. Paradigm involved pairing the rare tone with shock. B. P3-like ERPs developed over course of conditioning, as seen in sequential blocks of 400 trials each. C. Conditioning also led to pupillary dilation that anticipated shock. Reprinted with permission of Elsevier Publishers from O'Conner T, Starr A (1985).

$\mathrm{Cz}$. Over roughly the same latency range, recordings from contacts in and near the thalamus showed large negative deflections (see Yingling and near the thatamian sor similar results in another patient). Only six intracranial recording sites were used in the two patients, so the results in cats provided more thorough distributional information. It is also notable that this study more thorough distributional information. It is also notable that the humans using a conditioning paradigm of the sort used in animal studies. 
In another study with the same paradigm, the animal model was applied to study the effects of carbachol microinjection into the pontine reticular formation (Katayama et al., 1985b). This procedure is known to produce a state resembling coma, but it is unclear whether the behavioral unresponsiveness arises simply from a suppression of motor capabilities or whether information processing is also impaired. The results supported the latter hypothesis, in that P3-like ERPs disappeared concurrently with the carbachol-induced unresponsiveness. Given that carbachol is a cholinergic agonist, the authors concluded that the cholinoceptive pontine inhibitory area "may normally function to suppress excessive attendance to external stimuli." Furthermore, pilot data (cited by DeSalles et al., 1987, who used the conditioning paradigm in a study of cerebral concussion) suggested that P3-like ERPs were enhanced by the cholinergic antagonist atropine.

P3-like ERPs in the awake cat have been studied using a slightly different classical conditioning paradigm (Buchwald and Squires, 1982). Stimulus sequences presented at a 1.5-sec ISI included a tone $(p=.05)$ as well as a soft click and a loud click $(p=.8$ and .15 , or .15 and .8 , in alternating blocks). During conditioning, the tone was paired with a shock to the supraorbital margin that began $1 \mathrm{sec}$ after tone onset. Conditioned responses to the tone in the form of eye blinks were noted. Before conditioning (i.e., in a passive condition), no ERPs with latencies greater than $75 \mathrm{msec}$ were consistently recorded. After conditioning, positive ERPs to the rare click were generally observed in the 200 - to $500-\mathrm{msec}$ latency range. P3-like ERPs were also found when stimulus omissions were substituted for the rare click. Subsequent work showed that whereas these P3-like ERPs could be elicited in young cats between 1 and 3 years old, little or no differential activity was exhibited in a group of aged cats between 11 and 23 years old (Harrison and Buchwald, 1985). Similarly, P3 in human subjects is known to decrease in amplitude as a function of age (e.g., Pfefferbaum et al., 1984; Picton et al., 1984). It should also be noted that abnormal ERP responses in aged cats were often associated with sustained conditioned responses, suggesting that these measures were somewhat independent. Further studies in young cats showed that the P3-like responses to rare clicks in this paradigm were unaffected by bilateral ablations of primary auditory cortex (Harrison, Buchwald, and Kaga, 1986) or of several areas of polysensory association cortex (Harrison et al., 1990). When lesions were made in the caudal hippocampus, P3-like ERPs were enhanced postoperatively in 5 cats, but abolished in 2 other cats (Kaga et al., 1992). In another study, however, highly consistent effects were reported after septal lesions (Harrison et al., 1987). In six cats, damaged areas included the medial septum and the vertical limb of the diagonal band of Broca and, as a result, acetylcholinesterase in other brain areas was depleted. P3-like ERPs were enhanced and delayed during the first week of recording, but in the second week the responses were absent. The authors related the time course of this effect to the time course of cholinergic terminal degeneration. Results from two other cats showed that P3-like ERPs did not change after areas rostral to the septum were damaged. Intracranial recording studies showed that P3-like ERPs with multiple polarity inversions were appearent in the medial temporal region (Kaga et al., 1992), paralleling results from humans and monkeys, but with more detailed mapping. In another study, P3-like ERPs were found in recordings from electrodes in the dorsal part of the medial septal area (Harrison and Buchwald, 1987), lending additional support to the hypothesis that cholinergic systems are critical for $\mathrm{P} 3$.

P3-like ERPs have also been recorded by another group using classical conditioning (Csépe, Karmos, and Molnár, 1987). Frequent and rare clicks were presented and the latter were followed $750 \mathrm{msec}$ later by a shock to the neck. Conditioning was monitored by heart rate and blink responses occurring in the interval between the rare click ( $p=.1$ or .03$)$ and the shock. As the conditioned responses developed, the rare click also elicited P3-like responses in the 200- to 300-msec latency range. This ERP was not elicited during an initial habituation phase (passive condition) and tended to decline in amplitude during a posttraining extinction phase. However, the authors noted in two of the four cats tested that amplitudes declined before the extinction phase while shock reinforcement was still being delivered, perhaps because of the decreased novelty of overtraining.

Instead of using conditioning, one group has recorded ERPs from freely moving cats using a passive paradigm (Başar-Eroglu and Başar, 1987). Tones were presented at a $2.6-\mathrm{msec}$ ISI and every fifth tone was omitted. ERPs were averaged by selecting responses to omitted tones on the basis of wakefulness and lack of movement. Peaks with latencies near $300 \mathrm{msec}$ were noted in recordings from the dorsal hippocampus in four cats. The authors used further analyses in both the time and frequency domains to relate the hippocampal responses to theta rhythms and to EEG synchronization occurring just prior to stimuli (see Başar and Stampfer, 1985). Further studies in this type of passive paradigm have shown that P3-like ERPs can be recorded in auditory cortex and reticular formation, but most reliably in the hippocampus, especially in the CA3 region (Başar-Eroglu, Başar, and Schmielau, 1991; Bașar-Eroglu et al., 1991b).

P3-like ERPs in the cat, in sum, appeared sensitive to stimulus probability and significance as manipulated by classical conditioning. These cross-species comparisons, however, are weakened by the restricted nature of the behavioral measures and by the divergence from conventional paradigms used to elicit P3 in humans. Pupillary or blink responses recorded from cats monitored the general effects of conditioning but may not have been highly correlated with the allocation of attention to the experimental stimuli. A manipulation could conceivably disrupt P3-like ERPs in a conditioning or passive paradigm, but not alter P3-like ERPs in a categorization paradigm. This weakness thus limits the conclusions that can be drawn from some of the experimental results, especially those found using repetitive testing sessions. 


\section{Rabbit}

ERPs have been studied in rabbits using a discriminative conditioning paradigm that has traditionally been used to study the neural mechanisms of conditioning (Stolar et al., 1989). (Discriminative nictitating membrane conditioning has also been used; see Weisz et al., 1983). In this avoidance task, rabbits learned to avoid shocks by locomoting in an activity wheel (the conditioned response). Shocks were delivered $5 \mathrm{sec}$ after a tone unless the conditioned response was made. Tones of two frequencies were used, only one of which was paired with shock. Recordings were made after training during conditions in which the probabilities of the two tones were manipulated. In one condition, the two tones $(p=.2$ and .8$)$ were presented at a 1 -sec ISI in the absence of shocks and with no wheel movement possible to parallel conventional oddball paradigms (Fig. 7). Epidural ERPs differed as a function of probability in that a positive peak between about 100 to $200 \mathrm{msec}$ was more positive for the rare tone than for the frequent tone. These differences were evident when the rare tone had been paired with shock but not when the frequent tone had been paired with shock. This finding parallels evidence from humans showing target effects on P3 (DuncanJohnson and Donchin, 1977), although such target effects are generally much smaller; unfortunately, data are not available to determine whether P3 in humans would show this strong of a target effect under exactly the same conditions. ERP differences were also found in recordings from the dentate gyrus and the medial dorsal nucleus of the thalamus. Enhanced unit responses to the rare tone that had been paired with shock were found at several brain locations but at a somewhat longer latency. The authors interpreted their results to implicate an involvement of hippocampal and thalamic brain areas, but also noted that ERPs differed substantially from human ERPs in that the enhanced positive potentials occurred at a much earlier latency. Indeed, it is curious that the latencies of positive ERPs recorded in this study differed from those found in the following study.

Another group recorded ERPs from rabbits during a signal-detection task (Aleksandrov and Maksimova, 1985, 1987). Freely moving rabbits were trained to press a lever after a light flash to receive a food reinforcement. Each trial was initiated when the rabbit was positioned appropriately on a platform; position was determined by means of an infrared light attached to the rabbit's head. Within $0.5-10 \mathrm{sec}$ later, a series of four to seven light flashes was presented at a 1-sec ISI. Signal intensity began at a subthreshold level and was gradually increased. The rabbit was able to obtain food by running from the platform to press a level within $700 \mathrm{msec}$ after a flash. P3-like ERPs were elicited by detected flashes but not by undetected flashes. Somewhat smaller potentials were associated with false alarms. In ERPs averaged from 10 rabbits, the onset latency was $113 \mathrm{msec}$ and the peak latency was $414 \mathrm{msec}$. Concurrent recordings of unit activity during this paradigm showed that units in visual cortex and motor cortex tended to be

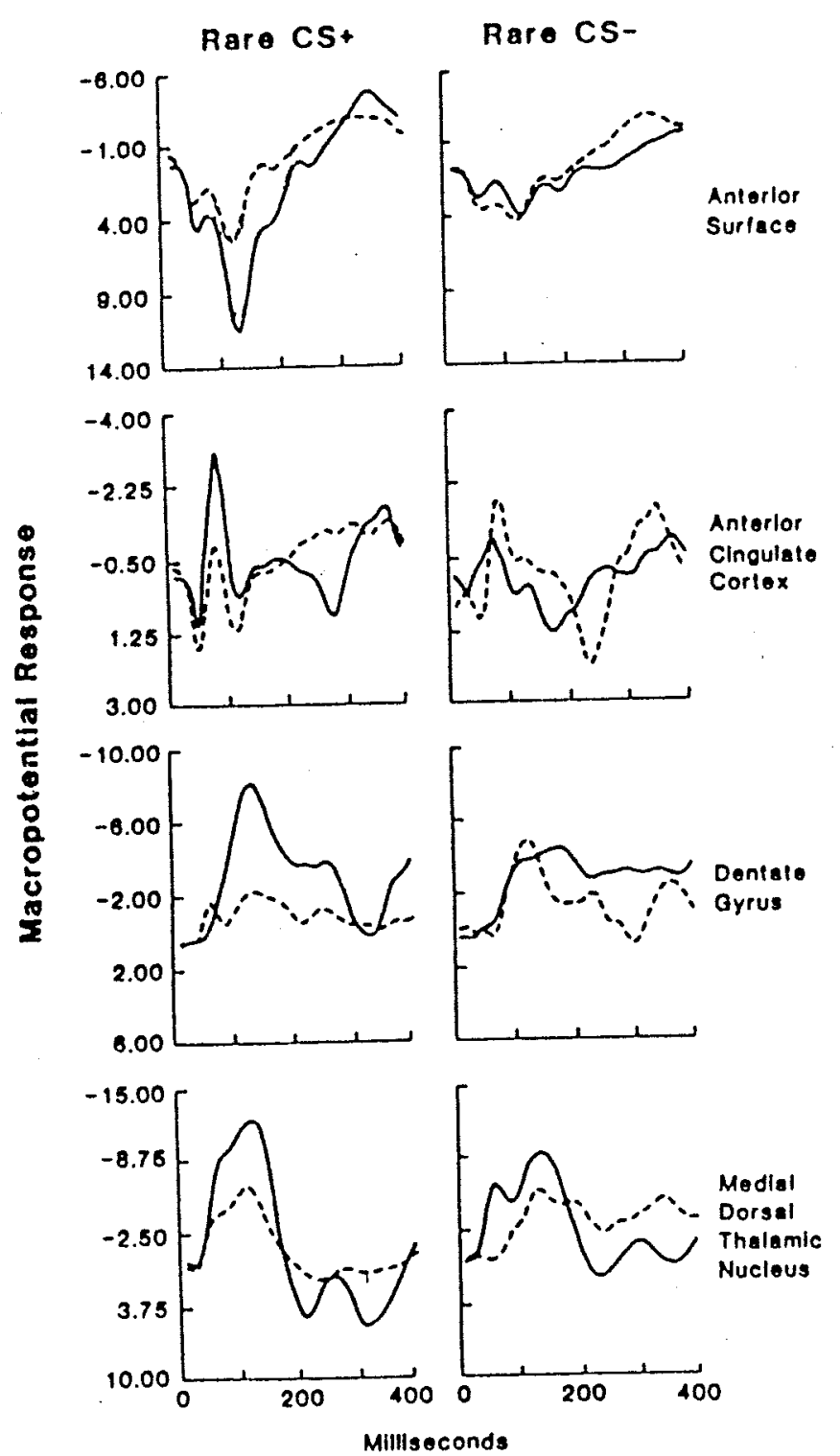

Figure 7. ERPs in form of $z$ scores derived from recordings in rabbits. P3-like ERPs were elicited after conditioning in which a rare tone had been paired with shock (CS,$+ p=.2)$. (See Stolar et al., 1989.) (Figure continued on next page.) 
Rare CS+

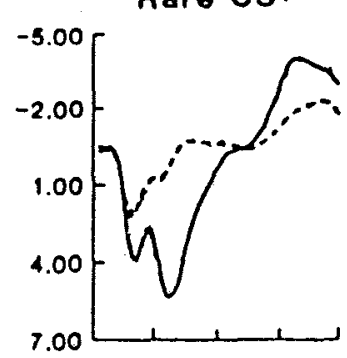

Rare CS-

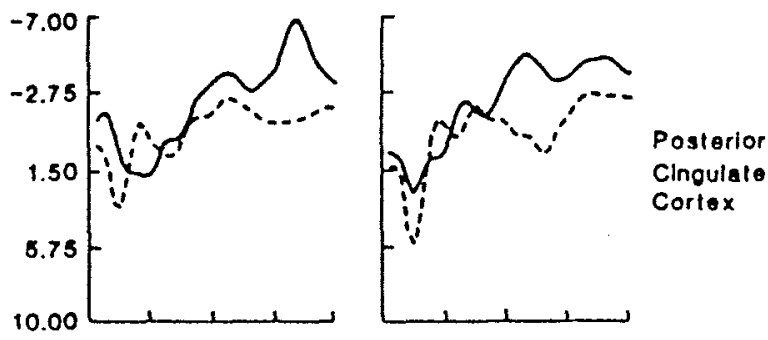

cs+

$---\operatorname{cs}-$

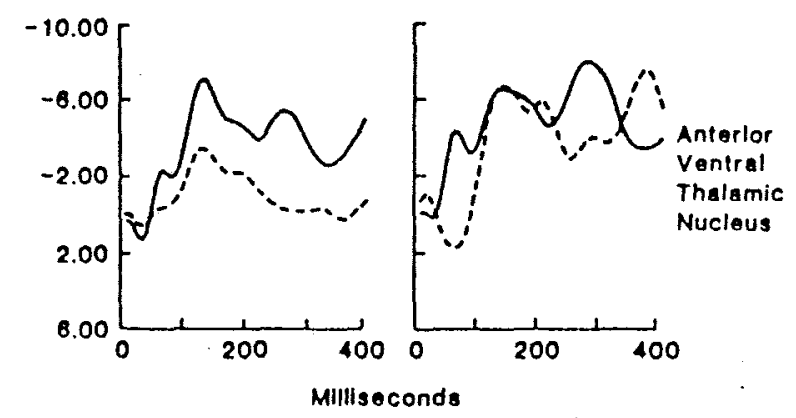

Figure 7. (continued)

activated simultaneously during the time that the amplitude of the P3-like response was increasing (Aleksandrov and Maksimova, 1987). Further, human subjects tested in a parallel paradigm exhibited P3 waves in response to detected flashes. Indeed, signal-detection paradigms comparable to this paradigm have been used in many studies of $\mathrm{P} 3$ in humans (e.g., Cooper et al., 19.77; Squires, Squires, and Hillyard, 1975). Whereas this paradigm differs somewhat from the usual categorization paradigm, it appears to be wellsuited for studying P3-like ERPs in animals and thus deserves further study.

Rat

Promising evidence for the existence of P3-like ERPs in rats has been obtained using several different paradigms. In one report, P3-like ERPs with peaks between 300 and $400 \mathrm{msec}$ were elicited by a rare tone $(p=.1)$ in a passive paradigm as well as in a conditioning paradigm (Hurlbut, Lubar, and Satterfield, 1987). In the conditioning paradigm, the rare tone was paired with a foot shock that the rat could avoid by moving to the opposite side of the experimental chamber. After criterion performance in avoidance conditioning was reached, ERPs were recorded in the absence of reinforcement. However, the frequent tone $(p=.9)$ was delivered at a frequency that was not as audible as that of the rare tone, thus confounding the comparison. This underscores the importance of taking into account the sensory and behavioral capabilities of the subjects when selecting stimuli and tasks.

In another passive paradigm, the frequency and intensity of three stimuli were adjusted such that the early ERP components were similar (Yamaguchi, Globus, and Knight, 1993). P3-like ERPs were elicited by two types of rare tones (Fig. 8). This paradigm thus appears to be a suitable one for further studies of the neural substrates of these potentials.

In another experiment, occasional auditory stimuli were interspersed in sequences of tactile stimuli, and vice versa (O'Brien, 1982; see also WirtzBrugger et al., 1986). However, these results are difficult to interpret, because recordings were made under anesthesia, which can eliminate P3 in human subjects (Fowler et al., 1988), and because this sort of bimodal paradigm has seldom been used to elicit $\mathrm{P} 3$ in human subjects.

ERPs have also been elicited using a categorization paradigm (Brenner et al., 1987). Rats were trained to respond to brief $(10-\mathrm{msec})$ light flashes by pressing one of two levers to receive food. Lights over one lever or the other lever were flashed on a random basis whenever $4 \mathrm{sec}$ had elapsed since the last lever-press. Positive peaks near $140 \mathrm{msec}$ were elicited by detected flashes in sessions in which performance was near perfect but not in sessions in which performance was poor. Positive ERPs were also elicited by bright flashes from another source that were delivered either predictably (rate 1 per $\mathrm{sec}$ ) or unpredictably (average rate 1 per min). Results obtained after noradrenergic denervation achieved by an injection of the neurotoxin DSP4 showed no changes in behavioral performance or ERPs, except that the responses to unpredictable flashes included an additional positive peak at about $280 \mathrm{msec}$. The authors concluded that the drug effect reflected a role of noradrenergic systems in inhibiting responses to unexpected stimuli.

In another categorization paradigm, rats were trained to obtain food by pressing a lever after one of two lights was illuminated (Voorn et al., 


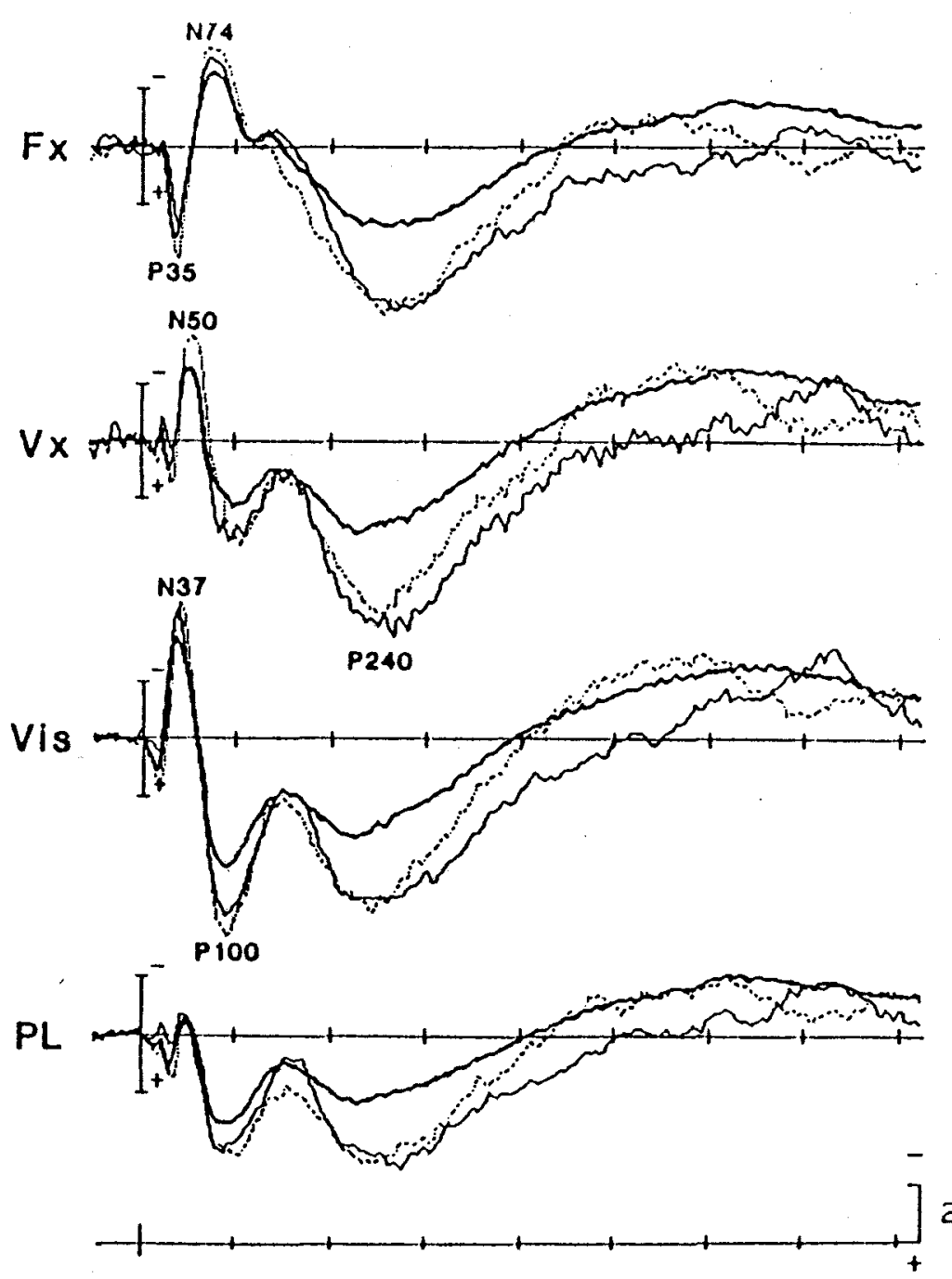

20 ull

$700 \mathrm{msec}$

\section{frequent pure tone $(\mathrm{BkHz}, \mathrm{BOdB})$ \\ infrequent pure tone $(2 \mathrm{kHz}, 76 \mathrm{~dB})$ complex tone $(71 \mathrm{~dB})$}

Figure 8. ERPs elicited in a passive condition in rats. P3-like ERPs were elicited by infrequent tones at epidural electrodes near frontal cortex $(\mathrm{Fx})$, vertex $(\mathrm{Vx})$, visual cortex (Vis), and posterior-lateral skull (PL). Reprinted with permission from Elsevier Science Publishers, Inc. from Yamaguchi et al. (1993).

1987). Presses while the other light was illuminated or while neither light was illuminated gave rise to a delay. ERPs were averaged for trials in which a correct response occurred within $600 \mathrm{msec}$ of light onset. Positive potentials with a peak between 300 and $500 \mathrm{msec}$ were exhibited in most subjects, preceded by a negative peak at $120 \mathrm{msec}$. Recordings within and near the hippocampus also revealed late potentials of both polarities and sporadic distribution. However, there was a great deal of unexplained variability across different recordings. Also, it is difficult to explain the differences between the potentials elicited in these categorization tasks and those elicited in passive paradigms (e.g., Fig. 8), given that the modality of stimulation was not the same. It should be noted that many other studies in rats have examined potentials elicited in the hippocampus. In particular, analyses of potentials elicited in the dentate gyrus during classical discriminative conditioning with two tones showed features somewhat analogous to those of P3 in humans, in that early responses (i.e., latencies $<150 \mathrm{msec}$ ) were responsive to the acquired significance of tones as well as to the pattern of immediately preceding tones (West et al., 1982; see also Hampson and Deadwyler, 1988).

\section{Other Animals}

Experiments with a bottlenose dolphin have revealed P3-like ERPs to auditory stimuli in two paradigms (Woods et al., 1986). Tones and digitized dolphin vocalizations were presented and stimulus types were balanced across conditions. In a passive paradigm, an ERP peak at a latency of $550 \mathrm{msec}$ was elicited by deviant stimuli and was enhanced as a function of probability (Fig. 9). In a conditioning paradigm in which one of several tones were differentially reinforced with food, the P550 deflection was elicited by the reinforced tone but also by some of the nonreinforced tones. The authors suggested that the prolonged latency of the P3-like ERP may have been associated with the advanced age of the dolphin.

ERPs were recorded from the frontal cortex in dogs in experiments using an appetitive conditioning paradigm (Koslov and Pirogov, 1988). Dogs were trained in classical conditioning using two tones, one of which was followed by a meat powder reinforcement. The reinforced tone elicited a series of deflections that appeared to be locally generated in an area in the medial part of the frontal lobe. The amplitude of these potentials decreased during extinction and varied as a function of the stimulus preceding the evoking stimulus, and thus may very well represent a P3-like phonomenon.

ERP recordings from chimpanzees and a gorilla have also been made in a passive paradigm (Boysen and Berntson, 1985). However, late positivity in scalp recordings was not readily apparent. This finding could reflect the young age of most of the animals (less than 11 weeks of age), the use of ketamine sedation in the older animals ( 2 juvenile chimpanzees aged 3-3.5 years), or shortcomings of the paradigm. The fact that flashes were presented 


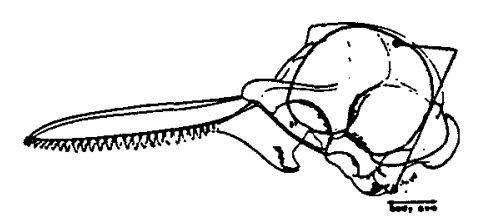

Figure 9. ERPs elicited in a passive condition in a dolphin. Rare auditory stimuli elicited a P3-like P550 deflection. Reprinted with permission of Lawrence Erlbaum Associates, Inc., from Woods DL, Ridgway SH, Carder DA, Bullock TH (1986): Middle- and long-latency auditory event-related

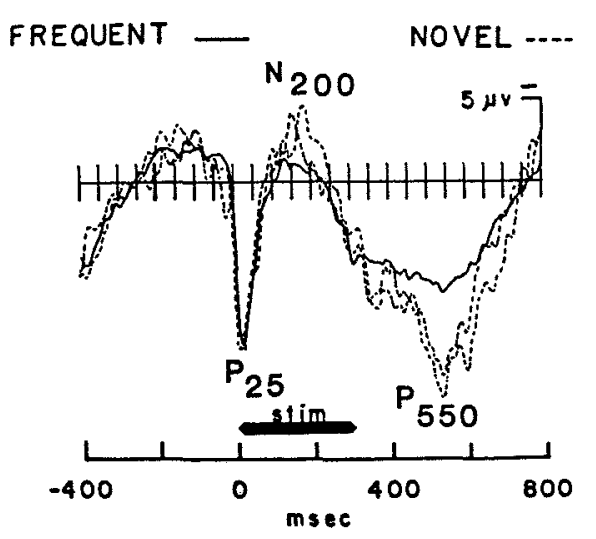
potentials in dolphins. In: Dolphin Cognition and Behavior: $A$ Comparative Approach, Schusterman RJ, Thomas JA, Wood FG, eds. Hillsdale, NewJersey: Lawrence Erlbaum Associates, Inc.

at a 1.4-sec ISI meant that they were highly predictable and unlikely to elicit P3 waves.

Diffuse flash stimuli, however, were used in more appropriate and inventive ways in experiments with elasmobranch and teleost fish (Bullock et al., 1990) and pond turtles (Prechtl and Bullock, 1990, 1992). ERPs recorded in the retina, optic tectum, and cortex were studied as a function of changes in flash intensity and duration. In particular, ERPs were elicited by stimulus omissions that occurred after a long train of flashes. These ERPs began $50-100 \mathrm{msec}$ after an omitted flash, were apparent in single trials, and lasted for as long as $1 \mathrm{sec}$. The ERPs were responsive to small changes in ISI, as if animals were developing expectations in some sense. The authors concluded that the ERPs reflected a rebound disinhibition and were not homologous to P3 in mammals, thus providing a cautionary note that paradigms designed to elicit cognitive ERPs may also elicit reflexlike responses because of slowly decaying neuronal activity that is unrelated to cognition (See Bullock, Karamürsal, and Achimowicz, 1993).

\section{Evaluating the Approach}

The variety of animal species in which P3-like responses have been recorded suggests that the underlying processes may be a universal feature of mammalian brains. The available evidence is consistent with the notion that many animals, not just humans, exhibit $\mathrm{P} 3$ responses, although the criteria by which these responses could be evaluated are far from exhausted. Further work will be needed to show that the neural characteristics of these potentials are indeed the same across species.

Given the goals of using ERPs to study the neural basis of cognition, it follows that waveform criteria are less important than functional criteria for validating P3-like ERPs. The most convincing support for an animal model of P3 would be evidence that homologous neural elements are activated during the very same circumstances. However, at present there is a high level of ignorance about the functional and neural properties of P3, compared to what may ultimately be learned. Studies of the functional and neural properties of $\mathrm{P} 3$ should thus progress in parallel with the development of animal models of $\mathrm{P} 3$.

Methodological concerns play a prominent role in this work, among them the following five issues.

1. The choice of species for these studies was in many cases pragmatic rather than reasoned. Initially, arguments for preferring some species over others can be made. Neuroanatomical similarities to humans and the ease with which behavioral tasks can be performed, for example, are important considerations. Also, close waveform similarities between species can give additional weight to the argument that parallel processes are being indexed.

2. A shortcoming of many studies was the lack of parallel results from humans. Studies should include human ERPs from comparable paradigms, when possible, to guarantee that the parameters used are appropriate for eliciting P3. This was particularly problematic for the conditioning paradigms because they have seldom been used with human subjects.

3. Much effort has been spent to assure that the ERPs recorded were not contaminated by artifacts, particularly those produced by eye movements. Such steps are crucial because artifacts can masquerade as P3-like responses under certain circumstances.

4. In order to study the functional properties of P3-like ERPs, it is often useful to compare ERPs from different stimulus conditions. In particular, it can be helpful to show that P3-like ERPs are not elicited by frequent stimuli in an oddball paradigm, which requires an appropriately short ISI (e.g., $1 \mathrm{sec}$ ) and stimuli that are suitable for the animal under study.

5. Caution is required in interpreting results from conditioning paradigms because of the possibility that the behavioral measures used are insufficient to verify that subjects are attending to the stimuli. In addition, evidence was cited suggesting that P3-like ERPs in conditioning paradigms as well as in passive paradigms tend to habituate, which poses problems for the use of longitudinal experimental manipulations such as in lesion and drug studies. Further, task manipulations in categoriza- 
tion paradigms, such as comparisons as a function of whether the subjects are attending to the stimuli, are critical for demonstrating the relationship between P3-like ERPs and cognition.

The primary usefulness of the animal models will arise from the application of techniques for exploring the neural basis of $\mathrm{P} 3$, and from building connections between our conceptions of the neural events underlying P3 and neural events that can be studied using the full repertoire of available neurophysiological techniques. This approach may still be in its infancy, but much relevant evidence has already been obtained. Intracranial recordings have shown that many brain areas are active at the time that $\mathrm{P} 3$ is produced. The hippocampus has held a prominent role in these studies for several reasons. Extremely high-amplitude potentials are produced there, perhaps because of synchronous activity in large numbers of hippocampal cells that are spatially aligned. The hippocampus has also been related to P3 because it receives input from all modalities, it plays an important role in memory functions (as has been suggested for P3), and it can be affected by diseases known to be associated with abnormal P3 potentials. Nevertheless, ample evidence implies that the integrity of the hippocampus is not required for normal P3 waves to be produced at the scalp (e.g., Onofrj et al., 1991, 1992; Paller et al., 1988; Potter et al., 1993) even though P3-like potentials can be elicited in the hippocampus (Halgren et al., 1980; McCarthy et al., 1989; Paller et al., 1992). This state of affairs leads naturally to the hypothesis that P3 arises from diffuse systems that innervate both the hippocampus and widespread neocortical areas. The norepinephrine system of the locus coeruleus and the acetylcholine system of the basal forebrain, in particular, have been investigated using animal models of P3. In squirrel monkeys, lesion and drug studies have accrued evidence that the locus coeruleus may be important for P3 (Pineda, Foote, and Neville, 1989; Swick, Pineda, and Foote, 1991). Several lines of evidence from studies in cats (e.g., Harrison and Buchwald, 1987) have provided very convincing support for the notion that acetylcholine systems of the basal forebrain are instrumental in the generation of $\mathrm{P} 3$. Converging evidence implicating particular neurochemical systems in human subjects can be obtained via drug studies. For example, some results suggest that P3 is disrupted by clonidine, which suppresses locus coeruleus firing (Duncan and Kaye, 1987), as well as by scopolamine, which is a cholinergic antagonist (Meador et al., 1987, 1989; Potter et al., 1992; Rugg et al., 1989). The finding that some drug effects occurred for stimuli presented in the auditory modality but not the visua modality is not well understood, but it underscores the need to study P3-like ERPs in both modalities. More work is needed to clarify how the different mechanisms that are activated in the two modalities relate to P3, and studies in both humans and nonhuman animals may prove useful in this regard.

In conclusion, the clinical and experimental use of P3 is limited by the fact that alterations in $\mathrm{P} 3$ cannot be rigorously associated with specific neural processes. An enhanced understanding of the neural bases of P3 may thus have widespread clinical application, as well as important implications for basic research on $\mathrm{P} 3$. One particularly vexing problem in P3 research has been the difficulty of identifying P3 across different experimental tasks. This component identification problem may be solved only after neural characteristics of P3 can supplement the waveform characteristics that have proven so ambiguous. Although the past three decades of study have accumulated a large literature on P3, basic questions about its neural and functional underpinnings are still enigmatic. The question "what is P3?" cannot be answered in any profound way without a better understanding of its neural basis. Further study of the comparative psychophysiology of P3, however, holds much promise for solving this mystery by clarifying the significance of the neural mechanisms that are put into play whenever $\mathrm{P} 3$ is produced.

Acknowledgments. Work on this review was supported by NIMH grant MH-05286, the Dept. of Veterans Affairs, the Institute of Cognitive Studies at the University of California, Berkeley, and the Dept. of Cognitive Science at the University of California, San Diego. I thank Truett Allison, Ted Bullock, and Marta Kutas for their comments on the manuscript, Maria Stone for her help with translations from Russian, and Bob Galambos and Steve Hillyard for inspiring me to look at ERPs in animals in the first place.

\section{References}

Aleksandrov IO, Maksimova NE (1985): P300 and psychophysiological analysis of the structure of behavior. Electroencephalogr Clin Neurophysiol 61:548-558.

Aleksandrov IO, Maksimova NE (1987): Slow brain potentials and their relation to the structure of behavior: Data on cortical unit activity. Electroencephalogr Clin Neurophysiol (Suppl.) 40:3-7.

Antal A, Bodis-Wollner I, Ghilardi MF, Glover A, Mylin L, Toldi J (1993): The effects of levo-acetyl-carnitine in visual cognitive evoked potentials. Electroencephalogr Clin Neurophysiol 86:268-274.

Arthur DL (1985): Long-latency auditory event-related potentials in behaving monkeys (doctoral dissertation, University of California, Irvine). Diss Abstr Int 46B:3349.

Arthur DL, Starr A (1980): Task-relevant late positive component of the auditory event-related potential in monkeys resembles P300 in humans. Science 223: $186-188$.

Başar E, Stampfer HG (1985): Important associations among EEG-dynamics, eventrelated potentials, short-term memory and learning. Int $J$ Neurosci 26:161180.

Başar-Eroglu C, Basar E (1981): Endogenous components of event-related potentials in hippocampus: An analysis with freely moving cats. Electroencephalogr Clin Neurophysiol (Suppl.) 40:440-444.

Başar-Eroglu C, Başar E, Schmielau F (1991a): P300 in freely moving cats with intracranial electrodes. Int $J$ Neurosci 60:215-226. 
Başar-Eroglu C, Schmielau F, Schramm U, Schult J (1991b): P300 response of hippocampus analyzed by means of multielectrodes in cats. Int $J$ Neurosci 60:239-248

Becker DE, Shapiro D (1980): Directing attention toward stimuli affects the P300 but not the orienting response. Psychophysiology 17:385-389.

Bodis-Wollner I (1990): Physiological effects of acetyl-levo-carnitine in the central nervous system. Int J Clin Pharmacol Res 10:109-114.

Boysen ST, Berntson GG (1985): Visual evoked potentials in the great apes. Electroencephalogr Clin Neurophysiol 62:150-153.

Brenner E, Mirmiran M, Overdijk J, Timmerman M, Feenstra MGP (1987): Effect of noradrenergic denervation on task-related visual evoked potentials in rats. Brain Res Bull 18:297-302.

Buchwald JS, Squires NS (1982): Endogenous auditory potentials in the cat: A P300model. In Woody CD, ed., Conditioning: Representation of the Involved Neural Function, pp. 503-515. New York: Plenum.

Bullock TH, Hofmann MH, Nahm FK, New JG, Prechtl JC (1990): Event-related potentials in the retina and optic tectum of fish. $J$ Physiol 64:903-914.

Bullock TH, Karamürsel S, Achimowicz JZ (1993): Two types of event related potentials to omission of stimuli in humans. Soc Neurosci Abstr 19:1605.

Cheney D, Seyforth R (1992): How monkeys see the world. Behav Brain Sci 15:135-182.

Cooper R, McCallum WC, Newton P, Papakostopoulos D, Pocock PC, Warren WJ (1977): Cortical potentials associated with the detection of visual events. Science 196:74-77.

Csépe V, Karmos G, Molnár M (1987): Effects of signal probability on sensory evoked potentials in cats. Int $J$ Neurosci 33:61-71.

Dale AM, Sereno MI (1993): Improved localization of cortical activity by combining EEG and MEG with MRI with cortical surface reconstruction: A Linear approach. $J$ Cognit Neuro 5:162-176.

DeSalles AAF, Newlon PG, Katayama Y, Dixon E, Becker DP, Stonnington $\mathrm{HH}$, Hayes RL (1987): Transient suppression of event-related evoked potentials produced by mild head injury in the cat. $J$ Neurosurg 66:102-108.

Desmedt JE (1981): Scalp-recorded cerebral event-related potentials in man as point of entry into the analysis of cognitive processing. In: The Organization of the Cerebral Cortex, Schmitt FO, Worden FG, Adelman G, Dennis SD, eds., pp. 441-473. Cambridge: MIT Press.

Desmedt JE, Debecker J (1979): Waveform and neural mechanisms of the decision P350 elicited without prestimulus CNV or readiness potential in random sequences of near-threshold auditory clicks and finger stimuli. Electroencephalogr Clin Neurophysiol 47:648-670.

Donchin E, Cohen L (1967): Averaged evoked potentials and intramodality selective attention. Electroencephalogr Clin Neurophysiol 22:537-546.

Donchin E, Otto D, Gerbrandt LK, Pribram KH (1971): While a monkey waits: Electrocortical events recorded during the foreperiod of a reaction time study. Electroencephalogr Clin Neurophysiol 31:115-127.

Duncan CC, Kaye WH (1987): Effects of clonidine on event-related potential measures of information processing. Electroencephalogr Clin Neurophysiol (Suppl.) 40:527-531.
Duncan-Johnson CG, Donchin E (1971): On quantifying surprise: The variation of event-related potentials with subjective probability. Psychophysiology 14:456-467.

Ehlers CL (1988): ERP responses to ethanol and diazepam administration in squirrel monkeys. Alcohol 5:315-320.

Ehlers CL (1989): EEG and ERP responses to naloxone and ethanol in monkeys. Psychopharmacal Biol Psychiatry 12:217-228.

Fabiani M, Gratton G, Karis D, Donchin E (1987): The definition, identification and reliability of measurement of the $\mathrm{P} 300$ component of the event-related brain potential. In: Advances in Psychophysiology, Vol. 2, Acklis PK, Jennings JR, Coles MGH, eds., pp. 1-78. Greenwich: JAI Press.

Ford JM, Roth WT, Kopell BS (1976): Auditory evoked potentials to unpredictable shifts in pitch. Psychophysiology 13:32-39.

Fowler B, Kelso B, Landolt J, Porlier G (1988): The effects of nitrous oxide on P300 and reaction time. Electroencephalogr Clin Neurophysiol 69:171-178.

Fuster JM, Willey TJ, Riley DM, Ashford JW (1982): Effects of ethanol on visual evoked responses in monkeys performing a memory task. Electroencephalogr Clin Neurophysiol 53:621-633.

Galambos R, Hillyard SA (1981): Electrophysiological approaches to human cognitive processing. Neurosci Res Program Bull 20:141-265.

Galambos R, Sheatz GC (1962): An electroencephalographic study of classical conditioning. Am J Physiol 203:173-184.

Glover AA, Onofrj MC, Ghilardi MF, Bodis-Wollner I (1986): P300-like potentials in the normal monkey using classical conditioning and an auditory 'oddball' paradigm. Electroencephalogr Clin Neurophysiol 65:231-235.

Glover A, Ghilardi MF, Bodis-Wollner I, Onofrj M (1988): Alterations in eventrelated potentials (ERPs) of MPTP-treated monkeys. Electroencephalogr Clin Neurophysiol 71:461-468.

Glover A, Ghilardi MF, Bodis-Wollner I, Onofrj M, Mylin LH (1991): Visual 'cognitive' evoked potentials in the behaving monkey. Electroencephalogr Clin Neurophysiol 90:65-72.

Goodin DS, Aminoff MD (1987): Electrophysiological differences between demented and nondemented patients with Parkinson's disease. Ann Neurol 21:90-94.

Gordon E, Sloggett G, Harvey I, Kraiuhin C, Rennie C, Yiannikas C, Meares R (1987): Magnetoencephalography: Locating the source of P300 via magnetic field recording. Clin Exp Neurol 23:101-110.

Halgren E, Squires NK, Wilson CL, Rohrbaugh JW, Babb TL, Crandall PH (1980): Endogenous potentials generated in the human hippocampal formation and amygdala by infrequent events. Science 210:803-805.

Hampson RE, Deadwyler SA (1988): Reflections on closure and context, with a note on the hippocampus. 'Behav Brain Sci 11:385-386.

Harrison J, Buchwald H (1985): Aging changes in the cat P300 mimic the human. Electroencephalogr Clin Neurophysiol 62:227-234.

Harrison JB, Buchwald JS (1987): A cat model of the P300: Searching for generator substrates in the auditory cortex and medial septal area. Electroencephalogr Clin Neurophysiol (Suppl.) 40:473-480.

Harrison J, Buchwald J, Kaga K (1986): Cat P300 present after primary auditory cortex ablation. Electroencephalogr Clin Neurophysiol 63:180-187.

Harrison JB, Dickerson LW, Song S, Buchwald JS (1990): Cat-P300 present after association cortex ablation. Brain Res Bull 24:551-560. 
Harrison JB, Buchwald JS, Kaga K, Woolf NJ, Butcher LL (1987): 'Cat P300' disappears after septal lesions. Electroencephalogr Clin Neurophysiol 69:55-64.

Hillyard SA, Bloom FE (1982): Brain functions and mental processes. In: Animal Mind-Human Mind, Griffin DR, ed., pp. 13-32. Berlin: Springer-Verlag.

Hillyard SA, Kutas M (1983): Electrophysiology of cognitive processing. Annu Rev Psychol 34:33-61.

Hillyard SA, Squires KC, Bauer JW, Lindsay PH (1971): Evoked potential correlates of auditory signal detection. Science 172:1357-1360.

Hurlbut BJ, Lubar JF, Satterfield SM (1987): Auditory elicitation of the P300 event-related potential in the rat. Physiol Behav 39:483-487.

John ER (1963): Neural mechanisms of decision making. In: Information Storage and Neural Control, Fields WS, Abbott W, eds., pp. 243-282. Springfield: Thomas.

Johnson R, Jr. (1988): Scalp-recorded P300 activity in patients following unilateral temporal lobectomy. Brain 111:1517-1529.

Kaga K, Harrison JB, Butcher LL, Woolf NJ, Buchwald JS (1992): Cat 'P300' and cholinergic septohippocampul neurons: Depth recordings, lesions, and choline acetyltransferase immuno-histochemistry. Neurosci Res 13:53-71.

Katayama Y, Tsukiyama T, Tsubokawa T (1985a): Thalamic negativity associated with the endogenous late positive component of cerebral evoked potentials ( $\mathrm{P} 300)$ : Recordings using discriminative aversive conditioning in humans and cats. Brain Res Bull 14:223-226.

Katayama Y, Reuther S, Dixon CE, Becker DP, Hayes RL (1985b): Dissociation of endogenous components of auditory evoked potentials following carbachol microinjection into the cholinoceptive pontine inhibitory area. Brain Res 334:366371.

Knight RT (1984): Decreased responses to novel stimuli after prefrontal lesions in man. Electroencephalogr Clin Neurophysiol 59:9-20.

Knight RT, Scabini D, Woods DL, Clayworth CC (1989): Contributions of temporalparietal junction to the human auditory P3. Brain Res 502:109-116.

Koslov AP, Pirogov AA, (1988): Medlennie potenciale prefrontalnoi kori sobak i klassicheskii secretornii yslovnii reflex. [Slow potentials of dogs prefrontal cortex and classical secretery conditioned reflex.] $Z h$ Vyssh Nervn Deyat Im IP Pavlova 38:434-442.

Kutas M, McCarthy G, Donchin E (1971): Augmenting mental chronometry: The P300 as a measure of stimulus evaluation time. Science 197:792-795.

Kutas M, Hillyard SA, Volpe BT, Gazzaniga MS (1990): Late positive eventrelated potentials after commissural section in humans. $J$ Cognit Neurosci 2:258271.

McCarthy G, Donchin E (1981): A metric for thought: A comparison of P300 latency and reaction time. Science 211:77-80.

McCarthy G, Wood CC, Williamson PD, Spencer DS (1989): Task-dependent field potentials in human hippocampal formation. $J$ Neurosci 9:4253-4268.

Meador KJ, Loring DW, Adams RJ, Patel BR, Davis HC (1987): Central cholinergic systems and the P3 evoked potential. Int $J$ Neurosci 33:199:205.

Meador KJ, Loring DW, Davis HC, Sethi KD, Patel BR, Adams RJ, Hammond EJ (1989): Cholinergic and Serotonergic effects on P3 potential and recent memory. $J$ Clin Exp Neuropsych 11:252-260.

Neville HJ, Foote SL (1984): Auditory event-related potentials in the squirrel monkey: Parallels to human late wave responses. Brain Res 298:107-116.

O'Brien JH (1982): P300 in the rat. Physiol Behav 28:318-321.
O'Conner T, Starr A (1985): Intracranial potentials correlated with an event-related potential, P300, in the cat. Brain Res 339:27-38.

Okada YC, Kaufman L, Williamson SJ (1983): The hippocampal formation as a source of the slow endogenous potentials. Electroencephalogr Clin Neurophysiol $55: 417-426$.

Onofrj M, Ghilardi MF, Faricelli A, Bodis-Wollner I, Calvani M (1987): Effect of levo-acetylcarnitine on P300-like potentials of the normal monkey. Drugs Exp Clin Res 13:407-415.

Onofrj M, Fulgente T, Nibilio D, Malatestz G, Bazzano S, Colamartino P, Gambi D (1992): P3 recordings in patients with bilateral temporal lobe lesions. Neurol 42:1762-1767.

Onofrj M, Gambi D, Fulgente T, Bazzano S, Colamartino P (1991): Persistence of P3 component in severe amnestic syndrome. Electroencephalogr Clin Neurophysiol 78:480-484.

Paller KA (1986): Effects of medial temporal lobectomy in monkeys on brain potentials related to memory (Doctoral dissertation, University of California, San Diego). Diss Abstr Int 47B:4428.

Paller KA, Zola-Morgan S, Squire LR, Hillyard SA (1982): Late positive event-related potentials in cynomolgus monkeys (Macaca fasicularis). Soc Neurosci Abstr 8:975.

Paller KA, Zola-Morgan S, Squire LR, Hillyard SA (1988): P3-like brain waves in normal monkeys and in monkeys with medial temporal lesions. Behav Neurosci 102:714-725.

Paller KA, McCarthy G, Roessler E, Allison T, Wood CC (1992): Potentials evoked in human and monkey medial temporal lobe during auditory and visual oddball paradigms. Electroenceph Clin Neurophysiol 84:269-279.

Pfefferbaum A, Ford JM, Wenegrat BG, Roth WT, Kopell BS (1984): Clinical application of the P3 component of event-related potentials. Electroencephalogr Clin Neurophysiol 59:85-103.

Picton TW, Stuss DT, Champagne SC, Nelson RF (1984): The effects of age on human event-related potentials. Psychophysiology 21:312-325.

Pineda J, Foote SL, Neville HJ (1987): Long-latency event-related potentials in squirrel monkeys: Further characterization of wave form morphology, topography, and functional properties. Electroencephalogr Clin Neurophysiol 67:77-90.

Pineda J, Foote SL, Neville HJ (1989): Effects of locus coeruleus lesions on auditory, long-latency event-related potentials in monkey. $J$ Neurosci 9:81-93.

Pineda J, Foote SL, Neville HJ, Holmes TC (1988): Endogenous event-related potentials in monkey: The role of task relevance, stimulus probability and behavioral response. Electroencephalogr Clin Neurophysiol 70:155-171.

Pineda JA, Swick D (1992): Visual P3-like potentials in squirrel monkey: Effects of a nonadrenergic agonist. Brain Res Bull 28:485-491.

Polich J (1989a): Habituation of P300 from auditory stimuli. Psychobiology 17:19-28.

Polich J (1989b): P300 from a passive auditory paradigm. Electroencephalogr Clin Neurophysiol 74:312-320.

Potter DD, Pickles CD, Roberts RC, Rugg MD (1992): The effects of scopolamine on event-related potentials in a continuous recognition memory task. Psychophysiology 29:29-37.

Potter DD, Pickles CD, Roberts RC, Rugg MD, Paller KA, Mayes AR (1993): Visual and auditory $\mathrm{P} 300$ in a case of bilateral destruction of the medial temporal lobes following viral encephalitis. In: New Developments in Event-Related Potentials, Heinze HJ, Münte TF, Mangun GR, eds., pp. 319-327. Cambridge, MA:Birkhauser. 
Prechtl JC, Bullock TH (1990): Event-related potentials in tectum and cortex of freely moving turtles to visual stimuli. Soc Neurosci Abstr 16:920.

Prechtl JC, Bullock TH (1992): Barbiturate sensitive components of visual ERPs in a reptile. Neuro Report 3:801-804.

Prim M, Ojemann G, Lettich E (1983): Human cortical patterns of "P300" potentials to novel visual items. Soc Neurosci Abstr 9:655.

Pritchard WS (1981): Psychophysiology of P300: A review. Psychol Bull 89:506-540.

Richer F, Johnson RA, Beatty J (1983): Sources of late components of the brain magnetic response. Soc Neurosci Abstr 9:656.

Ritter W, Vaughan HG, Jr., Costa LD (1968): Orienting and habituation to auditory stimuli: A study of short term changes in averaged evoked responses. Electroencephalogr Clin Neurophysiol 25:550-556.

Roth WT, Ford JM, Lewis SJ, Kopell BS (1976): Effects of stimulus probability and task-relevance on event-related potentials. Psychophysiology 13:311-317.

Ruchkin DE, Sutton S (1978): Emitted P300 potentials and temporal uncertainty. Electroencephalogr Clin Neurophysiol 45:268-277.

Rugg MD, Pickles CD, Potter DD, Roberts RC (1991): Normal P300 following extensive unilateral medial temporal damage. J Neurol Neurosurg Psychiat 54:217222

Rugg MD, Potter DD, Pickles CD, Roberts RC (1989): Effects of scopolamine on the modulation of event-related brain potentials by word repetition. Soc Neurosci Abstr 15:245.

Scott T, McCarthy G, Paller KA, Wood CC (1989): Event-related potentials recorded from scalp and hippocampal formation in humans performing detection tasks. Soc Neurosci Abstr 15:478.

Simson R, Vaughan HG, Jr., Ritter W (1976): The scalp topography of potentials associated with missing visual or auditory stimuli. Electroencephalogr Clin Neurophysiol 40:33-42.

Simson R, Vaughan HG, Jr., Ritter W (1977): The scalp topography of potentials in auditory and visual discrimination tasks. Electroencephalogr Clin Neurophysiol 42:528-535.

Smith DBD, Donchin E, Cohen L, Starr A (1970): Auditory averaged evoked potentials in man during selective binaural listening. Electroencephalogr Clin Neurophysiol 28:146-152.

Smith ME, Halgren E, Sokolik M, Baudena P, Musolino A, Liegeois-Chauvel C, Chauvel P (1990): The intracranial topography of the P3 event-related potential during auditory oddball. Electroencephalogr Clin Neurophysiol 76:235-248.

Snyder E, Hillyard SA, Galambos R (1980): Similarities and differences among the P3 waves to detected signals in three modalities. Psychophysiology 17:112-122.

Squires NK, Squires KC, Hillyard SA (1975): Two varieties of long-latency positive waves evoked by unpredictable auditory stimuli in man. Electroencephalogr Clin Neurophysiol 38:387-401.

Squires NK, Donchin E, Squires KC, Grossberg S (1977): Bisensory stimulation: Inferring decision-related processes from the P300 component. J Exp Psychol Hum Percep Perform 3:299-315.

Squires KC, Wickens C, Squires NK, Donchin E (1976): The effect of stimulus sequence on the waveform of the cortical event-related potential. Science 193: $1142-1146$.

Stapleton JM, Halgren E, Moreno KA (1987): Endogenous potentials after anterior temporal lobectomy. Neuropsychologia 25:549-557.
Stolar N, Sparenborg S, Donchin D, Gabriel M (1989): Conditional stimulus probability and activity of hippocampal, cingulate cortical and limbic thalamic neurons during avoidance conditioning in rabbits. Behav Neurosci 103:919-934.

Sutton S, Braren M, Zubin J, John ER (1965): Evoked potential correlates of stimulus uncertainty. Science 150:1187-1188.

Sutton S, Tueting P, Zubin J, John ER (1967): Information delivery and the sensory evoked potential. Science 155:1436-1439.

Swick D, Pineda JA, Foote SL (1991): Unit activity in the nucleus locus coeruleus related to P300-like potentials? Soc Neurosci Abstr 17:657.

Swick D, Pineda JA, Foote SL (in press): Effects of systemic clonidine on auditory event-related potentials in squirrel monkeys. Brain Res Bull (in press).

Trahms L, Stehr R, Erné SE, Seibertz E, Friederici AD (1990): Biomagnetic registration of P300 activity. J Clin Exp Neuropsychol 12:401.

Treisman A, Gelade G (1980): A feature-integration theory of attention. Cognit Psychol 12:97-136.

Verleger R (1988): Event-related potentials and cognition: A critique of the contextupdating hypothesis and an alternative interpretation of P3. Behav Brain Sci $11: 343-356$.

Voorn FJ, Adamse H, Kop PFM, Brunia CHM (1987): Hippocampal potentials related to signal stimuli in unrestrained rats. Electroencephalogr Clin Neurophysiol (Suppl.) 40:493-498.

Weisz DJ, McCarthy G, Wood CC, Thompson DT (1983): Event-related potentials reflect stimulus significance during discriminative NM conditioning in the rabbit. Soc Neurosci Abstr 9:642.

West MO, Christian E, Robinson JH, Deadwyler SA (1982): Evoked potentials in the denate gyrus reflect the retention of past sensory events. Neurosci Let 28: 319-324.

Wickens C, Kramer A, Vanasse L, Donchin E (1983): Performance of concurrent tasks: A psychological analysis of the reciprocity of information-processing resources. Science 221:1080-1082.

Wilder MB, Farley GR, Starr A (1981): Endogenous late positive component of the evoked potential in cats corresponding to P300 in humans. Science 211:605-607.

Wirtz-Brugger F, McCormack K, Szemczak M, Fielding S, Cornfeldt M (1986): P300 in anesthetized rat: Possible model for detecting memory-enhancing drugs. Soc Neurosci Abstr 12:713.

Wood CC, McCarthy G, Allison T, Goff WR, Williamson PD, Spencer DD (1982): Endogenous event-related potentials following temporal lobe excisions in humans. Soc Neurosci Abstr 8:976.

Wood CC, McCarthy G, Squires NK, Vaughan HG, Woods DL, McCallum WC (1984): Anatomical and physiological substrates of event-related potentials: Two case studies. In: Brain and Information: Event-Related Potentials, Karra R, Cohen J, Tueting P, eds., pp. 681-721. New York: New York Academy of Sciences.

Woods DL, Ridgway SH, Carder DA, Bullock TH (1986): Middle- and long-latency auditory event-related potentials in dolphins. In: Dolphin Cognition and Behavior: A comparative approach, Schusterman RJ, Thomas JA, Wood FG, eds., pp. 61-78. New Jersey: Erlbaum.

Yingling CD, Hosobuchi Y (1984): A subcortical correlate of P300 in man. Electroencephalogr Clin Neurophysiol 59:72-76.

Yamaguchi S, Globus H, Knight RT (1993): P3-like potential in rats. Electroencephalogr Clin Neurophysiol 88:151-154. 